\title{
SHEAR STRENGTHENING OF RC BEAMS WITH THIN PANELS OF MORTAR REINFORCED WITH RECYCLED STEEL FIBRES
}

Lúcio Lourenço ${ }^{\mathrm{a}}$, Ziaaddin Zamanzadeh ${ }^{\mathrm{b}}$, Joaquim A. O. Barros ${ }^{\mathrm{c}}$ and Mohammadali Rezazadeh ${ }^{\mathrm{d}}$

${ }^{a} \mathrm{PhD}$ Engineer (luciolourenco@civitest.com), CiviTest, Rua da Indústria, n. ${ }^{\circ}$ 144, 4770-160 Jesufrei, VN Famalicão, Portugal, Tel: +351 252315 199, corresponding author

b PhD Engineer (zia.zamanzadeh@gmail.com), Department of Civil Engineering, Bostanabad Branch, Islamic Azad University, Bostanabad, Iran. Tell: +989 144167502

c,d Full Professor (barros@civil.uminho.pt) ${ }^{\mathrm{c}}$ and Post-doc (rzh.moh@gmail.com) ${ }^{\mathrm{d}}$, ISISE member, Dep. Civil Engineering, University of Minho, Campus de Azurém, 4800-058 Guimarães, Portugal, Tel: +351 253510210 


\title{
Shear strengthening of $\mathrm{RC}$ beams with thin panels of mortar reinforced with recycled steel fibres
}

\begin{abstract}
The use of thin cement based panels reinforced with relatively high content of Recycled Steel Fibres (RSF) for the shear strengthening of Reinforced Concrete (RC) beams is investigated in the present work. The mechanical properties of this Recycled Steel Fibre Reinforced Mortar (RSFRM) are characterised. The panels are produced by using a mixing technique similar to the one used in the Slurry Infiltrated Fibre Concrete (SIFCon) technology. Then, their potentialities as a shear strengthening solution for RC beams deficiently reinforced in shear are investigated by performing three-point bending tests with RC beams of "I" cross section shape. The RSFRM panels are bounded in the lateral faces of the beams by using the two following strategies: (1) bonded to the concrete substrate by applying exclusively epoxy adhesive; and (2) besides epoxy adhesive, mechanical fasteners are applied. The applicability of an analytical approach for estimating the contribution of RSFRM panels for the shear resistance of RC beams is assessed, and a design example is presented.
\end{abstract}

Keywords: Recycled steel fibre, cement based mortar, shear strengthening, FEM analysis, numerical simulation, analytical approach.

\section{Introduction}

Reinforced Concrete (RC) beams are traditionally reinforced with steel stirrups to prevent shear failures. As shear failure is brittle in nature, the application of design codes recommendations (ACI Committee 318 2008, Eurocode 2004, NZS4203 1992) conducts to relatively high content of steel stirrups in the critical regions of RC framed structures, mainly in concrete elements of buildings in seismic risk zones, which can compromise the concrete casting quality. Moreover, strengthening and repairing of RC structures are often required due to change in their use, degradation of their constituent materials along the time, and structural damage caused by earthquake, excessive loading or accidents (Baghi 2015).

Due to the above mentioned reasons, over the last years several strengthening techniques 
have been developed including externally bonded steel plates, fibre reinforced polymer (FRP) systems, external prestressing and reinforced concrete jacketing. The potentiality of using thin plates of Strain Hardening Cementitious Composites (SHCC) reinforced with Carbon Fibre Reinforced Polymer (CFRP) laminates for the shear strengthening and shear repairing of Reinforced Concrete (RC) beams has been explored by Baghi el al. (2016). SHCC is a class of Fibre Reinforced Cement Composites (FRCC) that exhibits ductile behaviour under tensile load, with a strain hardening response rather than the tension softening character presented by conventional FRCC after crack initiation (Li 1998).

On the other hand, recent research is showing that the addition of Recycled Steel Fibres (RSF) from post consumed tyres (Figure 1) can decrease significantly the brittle behaviour of cement based materials, by improving its toughness and post-cracking resistance (Domski et al. 2017, Zamanzadeh et al. 2015a, Aiello et al. 2009). The use of RSF as a reinforcement system of cementitious composites has also beneficial environmental and economic impacts, since an added commercial value is given to a subproduct of the tyre recycling industry that, in general, is considered a waste product (Zamanzadeh et al. 2015a, Graeff et al. 2012, Neocleous et al. 2006). With these objectives, the present paper explores the possibility of developing thin panels made by mortar reinforced with relatively high content of RSF (3.8\% in volume) for the shear strengthening of RC beams. A detailed description of the executed experimental research and a discussion of the obtained results are presented. The analytical approach proposed by Baghi et al. (2016) for predicting the capacity of RC beams shear strengthened with Hybrid Composite Plates (HCP) was adapted in order to extend its applicability to RC beams shear strengthened with the developed RSFRM panels. Finally, a design example of the shear strengthening of a real scale RC beam is provided to demonstrate the practical application of the proposed strengthening technique in the design context.

\section{Production of thin panels of mortar reinforced with recycled steel fibres}

\subsection{Composition and production technology of the RSFRM panels}

The RSFRM is composed of a cementitious mortar reinforced with RSF (fibre content of $3.8 \%$ in volume). The mortar mix was prepared based on the research already carried out in the technology of this composite (Zamanzadeh et al.2015b). The cement, fly ash and 
fine sand were put into a planetary mixer of 50 litres capacity and were mixed during one minute. Water was first mixed with the superplasticizer and, then, slowly added into the mixer for approximately two minutes. After this, viscosity modifying admixture was added, and the mixing continued during more two minutes. In each batch, approximately 16 litres of mortar were produced. Table 1 shows the mix proportions used.

The technique used for producing SIFCon was adopted for manufacturing the RSFRM thin panels. In this technique, after placing the RSF into the mould, the mortar is poured on fibres bed until the mould is filled up (Figure 2). An external vibration is applied during casting to ensure a good infiltration of the mortar.

\subsection{Mechanical properties of the RSFRM}

\subsubsection{Modulus of elasticity and compressive strength}

The value of the modulus of elasticity $\left(E_{c}\right)$ of the RSFRM was obtained in four cylindrical cores of $100 \mathrm{~mm}$ height and $50 \mathrm{~mm}$ diameter, by performing tests according to the LNEC E397 (1993). These cores were extracted from RSFRM panels with dimensions of $600 \mathrm{~mm} \times 150 \mathrm{~mm} \times 100 \mathrm{~mm}$ by using a drilling machine. An average value of $19.6 \mathrm{GPa}$ was obtained with a coefficient of variation $(\mathrm{COV})$ of $8 \%$.

After determining the modulus of elasticity, the same specimens were used for evaluating the compressive strength of the RSFRM according to NP EN 12390-3 (2011) recommendations, having been obtained an average compressive strength of $46.64 \mathrm{MPa}$ with a COV of $1 \%$.

\subsubsection{Flexural behaviour}

\subsubsection{Specimen details and test setup}

The flexural behaviour of RSFRM was investigated by performing three-point bending tests on notched and un-notched specimens. To evaluate the stress at crack initiation, the corresponding deflection and also the maximum flexural stress, eight un-notched RSFRM specimens with a length of $250 \mathrm{~mm}$ and a cross section of $50 \times 50 \mathrm{~mm}^{2}$ were tested. A Linear Variable Differential Transformer (LVDT) was used to measure the vertical 
deflection of the specimen during testing (Figure 3a). Five notched specimens with the same geometry of un-notched specimens were used to evaluate the contribution of the RSF for the post-cracking residual strength of the RSFRM. A notch of $9 \mathrm{~mm}$ depth and 2 $\mathrm{mm}$ width was made in the middle span of the specimens (perpendicular to the top casting surface). These dimensions of the notch are an updated scale of the dimensions of the notch proposed by Model Code 2010 for the characterization of fibre reinforced concrete. An LVDT was installed at the bottom face of the specimen, close to the notch mouth, in order to measurer the Crack Mouth Opening Displacement (CMOD) - see Figure 3b. The results of these tests were also used to estimate the fracture energy of the RSFRM (energy to propagate a crack of unit area), which is designated as mode I fracture energy, a measure of the ductility of the material.

\subsubsection{Flexural test results}

The results from the three-point bending tests with un-notched prisms are used to estimate the stress at crack initiation, which was determined from the following expression:

$$
\sigma_{c r}=\frac{3 F_{c r} \times L}{2 b \times h^{2}}
$$

where $F_{c r}$ is the cracking load, having been assumed as the load when a reduction of $10 \%$ in initial secant stiffness occurred. In equation (1), $b$ and $h$ are the width and height of the specimen's cross section, respectively. The average values of $6.18 \mathrm{MPa}, 0.231 \mathrm{~mm}$ and $9.51 \mathrm{MPa}$ were obtained for stress at crack initiation, corresponding mid span deflection and maximum flexural stress, respectively.

In Figure 4 the envelope and the average curve corresponding to the flexural stress vs. CMOD obtained in the tests with notched specimens are plotted. From the obtained results it is verified that a pronounced deflection hardening stage has occurred from crack initiation up to the peak load, followed by a pseudo plastic regime up to the ultimate crack width recorded in the executed tests $(3.5 \mathrm{~mm})$, which demonstrates the ductility of this material. The results also show that crack initiation has occurred at about $4 \mathrm{MPa}$ of flexural stress (the crack width at this stress level is, in fact, an elastic deformation recorded in the measuring length of the LVDT, see Figure 3b), followed by accentuated stage of deflection hardening of almost constant stiffness up to about $10 \mathrm{MPa}$ and $0.37 \mathrm{~mm}$ crack width. Above this crack width level, the stiffness has decreased smoothly 
up to a stage (corresponding to a crack with of about $0.94 \mathrm{~mm}$ ), above which the flexural capacity has remained almost constant up to the end of the test.

\subsubsection{Direct tensile behaviour}

\subsubsection{Direct tensile test setup and specimens}

Tensile specimens consisted of nine rectangular coupons with dimensions of $230 \mathrm{~mm} \times 50 \mathrm{~mm} \times 23 \mathrm{~mm}$ were extracted from two RSFRM panels with dimensions of $686 \mathrm{~mm} \times 188 \mathrm{~mm} \times 23 \mathrm{~mm}$ (Figure 5a). Five rectangular specimens were extracted in the longitudinal direction (identified by the label "RDTT0"), and four rectangular specimens were extracted at 45 degrees (identified by the label "RDTT45"). Three specimens were also prepared using dog-bone type moulds (identified by the label "DBDTT"). For ensuring constant thickness for the rectangular specimens, their top surface was rectified before testing, and thickness of $21 \mathrm{~mm}$ was measured for these specimens. The top surface of the dog-bone type specimens was not rectified, since it was possible to guarantee and almost constant thickness of $23 \mathrm{~mm}$ for these specimens.

Figure 5 shows details of the specimens, test setups, and monitoring devices used to evaluate the tensile strength and deformation of tested specimens. Aluminium tabs were applied to each end of the specimen by means of structural adhesive (Sikadur 32N). Then, the tabs were clamped within the wedges of the testing machine. Tensile specimens were tested under displacement control at a displacement rate of $0.5 \mathrm{~mm} / \mathrm{min}$.

\subsubsection{Direct tensile test results}

Figure 6a presents representative crack patterns of the tested specimens, from the beginning up to the end of a test. During the strain hardening phase of RSFRM, several cracks were formed up to the cracking stabilized stage. This indicates that the crack opening restrain provided by the fibre bridging action has led to the formation of several cracks in direct tension conditions of the specimen, which is a characteristic of strain hardening materials (Pereira et al. 2012). The results in terms of tensile stress vs. tensile strain of these tests are shown in Figure $6 b$ (stress is the applied load divided by the specimen's cross section area). Analysing these curves, three response stages are observable. The first stage corresponds to the linear behaviour of the uncracked specimen. 
When the tensile strength of the matrix is reached, the first crack was formed and a hardening stage has initiated up to the peak load. During this second stage several cracks were formed up to almost the peak load, where the cracking process has attained its stabilized stage. This was followed by a softening stage with a smooth decrease of the tensile capacity with the increase of the tensile strain. In this stage the opening process of the cracks already formed has progressed, therefore the tensile capacity is provided by the reinforcement mechanisms ensured by fibres bridging the formed cracks.

DBDTT specimens presented a less steep softening branch than RDTT0 and RDTT45, but at a tensile strain of about $2.5 \%$ all the tested specimens had an almost equal tensile capacity (of about $2.3 \mathrm{MPa}$ ), which corresponds to about $71 \%$ of the average tensile strength obtained in all the tested specimens (see Figure 6b).

The obtained results also demonstrate that the tensile behaviour of rectangular specimens extracted at 0 and 45 degrees was similar, which indicates the influence of fibre orientation and distribution was not significant in this respect, due to the technology adopted for the production of the RSFRM panels where these specimens were extracted.

\subsubsection{Shear behaviour of RSFRM}

\subsubsection{Test setup and monitoring system}

The objective of this section is to investigate the shear behaviour of the RSFRM by performing twelve V-Double edge notched Iosipescu specimen tests. Concerning about adopting a test setup to assure a uniform shear stress zone on the Iosipescu specimens to evaluate the shear behaviour of RSFRM, in addition to the use of an antisymmetric fourpoints bending loading configuration, a double notch was created in the region of the Iosipescu specimens with high shear and low bending moment. The specimens consist of a small beam height $\left(h_{0}\right)$, angle of notch root $(\alpha)$, and tip radius at notches $(r)$ (Figure 7).

The testing device used in the scope of the research carried out in this work was the one developed by Baghi and Barros (2016), Figure 8a. The fixture region of this device covers the entire contact regions of the specimen. The dimensions of the specimens were $380 \mathrm{~mm} \times 140 \mathrm{~mm} \times 15 \mathrm{~mm}$. The values of $25 \mathrm{~mm}, 90^{\circ}$, and $2.5 \mathrm{~mm}$ were adopted for 
the $h_{0}, \alpha$ and $r$, respectively (Figure 8b). The Iosipescu specimens were simultaneously casted with the panels used for the shear strengthening of the RC beams.

The specimens were tested in displacement control conditions at a deflection rate of 0.005 $\mathrm{mm} / \mathrm{s}$, taking the signal read in the internal displacement transducer (LVDT) of the servoactuator, and using a load cell of $10 \mathrm{kN}$ capacity for recording the applied load. The weight and slight friction of the movable portion of fixture was taken into account in the force values recorded in the load cell. At the loaded and notched section an LVDTs with the linear stroke of, respectively, $+/-50 \mathrm{~mm}$ and $+/-2.5 \mathrm{~mm}$, was installed according to the illustration in Figure 8a, in order to measure the displacement of the specimen and the sliding of the crack.

The average shear stress was determined by dividing the total applied load $(P)$ by the area of the cross section between the two notches $\left(375 \mathrm{~mm}^{2}\right)$ :

$$
\tau_{\text {avg }}=\frac{P}{A}
$$

The shear stress at crack initiation $\left(\tau_{c r}\right)$ is obtained from:

$$
\tau_{c r}=\frac{F_{c r}}{A}
$$

where $F_{c r}$ is the cracking load, having been assumed as the load when a reduction of $10 \%$ in initial secant stiffness has occurred.

\subsubsection{Iosipescu test results and discussion}

The results of the Iosipescu specimen tests in terms of the envelope and average curve corresponding to the average shear stress vs. sliding relationship are plotted in Figure 9a. Moreover, the typical crack pattern observed experimentally in the tested specimens is shown in Figure 9b.

Analysing the shear stress $v s$. sliding curve presented in Figure 9a, four distinct stages are observable. The first stage corresponds to the linear behaviour up to a shear stress of about 6.25 $\mathrm{MPa}$ (crack sliding equal to $0.02 \mathrm{~mm}$, which in reality is an elastic deformation of the RSFRM in the measuring zone), at which the initial vertical cracks have formed. The second stage is attributed to the hardening phase with formation of several micro cracks 
up to the peak load. The third stage corresponds to the first phase of the post-peak softening branch, where the micro cracks are degenerating in meso-cracks due to a connecting process between them that ended at a slide of about $1.5 \mathrm{~mm}$. Above this sliding level (second softening regime), the softening slope was smaller. At a sliding of about $4.5 \mathrm{~mm}$, which is circa 10 times higher than the sliding at the average peak load, the RSFRM is capable of supporting about $80 \%$ the average shear strength. This confirms the high ductility and shear strength capacity of this cementitious composite when subjected to shear deformations.

\subsection{Inverse analysis for assessing the fracture properties of RSFRM}

\subsubsection{Fracture mode I properties}

In the scope of the material nonlinear analysis of RSFRM using a smeared crack approach, the post-cracking tensile behaviour in fracture mode I propagation of smeared cracks formed in RSFRM was simulated by the trilinear softening diagram represented in Figure 10 (Barros et al. 2013). In this sense, the values of the fracture energy mode I and parameters defining the tensile softening diagram were numerically determined performing inverse analysis with the experimental results of the direct tensile and threepoint notched beam bending tests. For this purpose, FEMIX finite element analysis software (Barros 2016) was used. The specimens were modelled with Serendipity plane stress state Finite Elements (FEs) of 4 nodes, and adopting a Gauss-Legendre integration scheme of $2 \times 2$ integration points. To assure a crack propagation process restricted to the symmetry plane of the three-point notched beam bending specimen (almost resembling what was registered experimentally), the FEs located at the notched zone had $1 \times 2$ integration points. In the inverse analysis, a crack bandwidth $\left(l_{b}\right)$ equal to the width of the notch $(2 \mathrm{~mm})$ was assumed, which coincides with the width of the FEs above the notch. The finite element mesh used for the simulation of the flexural and direct tensile tests is represented in Figure 11a and 11b, respectively. It should be noted that due to the symmetry conditions of the tensile specimen in terms of geometry, supports and loading, only a quarter of this specimen was modelled.

The comparison between the experimental and numerical results in terms of load $v s$. CMOD and load vs. displacement relationships is shown in Figure 12a and Figure 12b, 
respectively. The values defining the fracture mode I constitutive law, $\sigma_{n}^{c r}-\varepsilon_{n}^{c r}$, obtained from inverse analysis, are presented in Table 2.

By comparing the results obtained from inverse analysis in the simulation of the direct tensile tests and three-point notched beam bending tests (see Table 2), it is verified that the values of tensile strength and fracture energy mode I obtained from the simulation of the three point notched beam bending tests are higher than the values obtained from the simulation of the direct tensile tests, which can be justified by different fibre pull-out mechanisms mobilized in these different tests.

In a bending test, the curvature introduced in the cracked cross section amplifies the snubbing effect represented in Figure 13 (Leung and Shapiro 1999, Cunha et al. 2010). Due to the $N_{y}$ force component occurring in an inclined fibre that is being pull-out, normal stress components, $\sigma_{N}$, are introduced in the loaded end slip zone of the fibre, which increases the resistance to the fibre slipping due to the Mohr-Coulomb effect. These extra fibre resisting mechanisms justify the above registered differences.

\subsubsection{Fracture mode II properties}

Fracture mode II parameters of the RSFRM were evaluated by performing an inverse analysis with the Iosipescu test results. For this purpose, the Iosipescu test was also simulated with FEMIX computer program (Barros 2016). The two-dimensional multidirectional fixed smeared crack model described in Ventura-Gouveia (2011) was used in the numerical simulations.

The trilinear tension-softening diagram was adopted to define the behaviour of RSFRM in terms of the crack initiation and fracture mode I propagation, as represented in Figure 10. The values derived from the inverse analysis with the direct tensile test results (see Table 2) were used to define the fracture mode I constitutive law, $\sigma_{n}^{c r}-\varepsilon_{n}^{c r}$. The RSFRM Young's modulus and compressive strength adopted in the numerical model are those obtained in the experimental programs presented in Section 2.2.1.

The adopted FE mesh for the Iosipescu specimens with the support and load conditions is represented in Figure 14. This FE mesh is composed by 2015 nodes and 1920 Serendipity 4 nodes plain stress elements with $2 \times 2$ Gauss-Legendre integration scheme. The comparison of the shear stress $v s$. sliding of the crack obtained numerically and 
registered experimentally at the notched plane for the tested specimens is illustrated in Figure 15. The sliding of the crack at the notched plane was assumed as the displacement of the node corresponding to the position of the aluminium plate that touches the piston of the LVDT at the notched section. Table 3 includes the values of the mode II fracture parameters (shear retention factor, $\beta$, crack shear strength, $\sigma_{t, p}^{c r}$, mode II fracture energy, $G_{f s}$ ) that were obtained from inverse analysis (a linear shear softening diagram was adopted).

\section{Assessment of the effectiveness of RSFRM panels for the shear strengthening of RC beams}

In this section the efficiency of RSFRM panels as a shear strengthening solution for RC beams is investigated. Three-point bending tests were performed with series of RC beams of "I" cross section shape deficiently reinforced in shear, and strengthened with RSFRM panels (see Figure 16).

\subsection{Shear strengthening technique}

RSFRM panels with the dimensions of $686 \mathrm{~mm} \times 186 \mathrm{~mm} \times 23 \mathrm{~mm}$ were produced and bonded in the lateral faces of the beams by using the two following strategies: applying exclusively epoxy adhesive (SB-E series); in addition to the epoxy adhesive, mechanical fasteners were also applied in an attempt of increasing the shear strengthening effectiveness provided by the RSFRM panels due to the extra concrete confinement promoted by these fasteners (SB-EM series). The properties of the used adhesive can be consulted elsewhere (Costa and Barros 2015). Reference beams without any type of shear reinforcement and strengthening (SB-C series) were also tested for comparison purpose. To apply the RSFRM panels to the lateral faces of the beams, firstly the surfaces of the beams were cleaned by compressed air and then an epoxy adhesive (S\&P220) layer of a thickness of about $1 \mathrm{~mm}$ was homogenously applied on the surfaces of the concrete beam to be in contact with the panels, as well as on the interior face of the RSFRM panels. The RSFRM panels were pressed against the lateral surfaces of the beam using mechanical clamps up to the time that the epoxy resin has developed sufficient bond strength to allow their removable. Two weeks after the RSFRM panels have been applied to the lateral faces of the beams, ten holes of $10 \mathrm{~mm}$ diameter were drilled through both panels and web of the SB-EM beams for the installation of the mechanical fasteners, as illustrated in 
Figure 17. Then, the RSFRM panels were confined to the concrete substrate of these beams with ten mechanical fasteners composed of bolts and nuts, by applying a torque of 20 N.m in the nuts on both sides of the beams.

\subsection{Test setup and groups of tests of the experimental program}

Figure 16 shows the test setup and position of the five LVDTs used to measure the beam's deflection. The geometry and reinforcement details of the three series of beams produced for this experimental program, as well as the loading and supporting conditions are illustrated in Figure 17. It should be noted that the reference beams (SB-C) had the same geometry of the other beams presented in this figure but without any type of shear strengthening. An average yield stress and tensile strength of $600.8 \mathrm{MPa}$ and $754.6 \mathrm{MPa}$ was obtained, respectively, by performing tensile tests in 4 coupons of steel stirrups according to EN 10002 recommendations. The properties of the flexural reinforcement were not assessed experimentally since flexural failure mode was not expected to occur in any of the tested RC beams, therefore this information was not considered relevant for the conclusions to be retrieved from this experimental program.

In the first phase of the experimental program three beams (one beam from each series) were tested. Since the beams SB-E1 and SB-EM1 unexpectedly failed at the support section before shear failure has occurred, in the second phase of the experimental program, a confinement system by using steel plates was applied to the beam's support sections (Figure 18). The labels SB-C2, SB-E2 and SB-EM2 identify the RC beams tested in the second phase. In the third phase, the effectiveness of this technique was explored for the shear repairing of pre-damaged RC beams (PSB-E). For this purpose, firstly the control beam in the first phase of the experimental program (SB-E1) was loaded up to its shear failure, and then fully unloaded. The RSFRM panels were bonded to this damaged beam by using epoxy adhesive, and the beam was tested again, as part of the third group of tests, with the designation of PSB-E1.

\subsection{Results and discussion}

The relationship between the applied load and the mid span deflection (LVDT3) of the tested series of beams is represented in Figure 19, while the crack patterns at their failure are shown in Figure 20. Due to deficient execution of the anchorage length of the longitudinal reinforcement in the SB-E1 and SB-EM1 beams, they failed prematurely at 
both supported zones (Figure 20b and 20c), which avoided to accurately estimate the real shear efficiency of the strengthening technique for these beams. In any case, all the strengthened and repaired beams presented much higher load carrying capacity than the reference beams (SB-C1 and SB-C2).

The maximum load capacity of the tested beams $\left(F_{\max }\right)$ and their corresponding deflection $\left(\Delta_{u}\right)$ are indicated in Table 4 , as well as $\Delta_{u} / \Delta_{u}^{S B-C i}$ and $F_{\max } / F_{\max }^{S B-C i}$, where $F_{\max }^{S B-C i}$ and $4_{u}^{S B-C i}$ are the maximum load capacity and corresponding mid span deflection of the SB$\mathrm{C}$ reference beams. The beam SB-E2 failed at a load level higher than the maximum load registered in SB-EM2 beam (see Table 4). In the first and second groups of tests, the $F_{\max } / F_{\max }^{S B-C i}$ varied between 2.07 and 2.55 , while the $\Delta_{u} / \Delta_{u}^{S B-C i}$ has ranged between 3.06 and 3.77. By comparing the results for these ratios in the first and second group of tests, it can be concluded that when premature failure of the supports of the beams of the first group has occurred, these beams were almost close to their shear capacity, mainly in the case of the SB-EM1 beam, which is also supported by the level of damages observed in Figure $20 \mathrm{~b}$ and 20c.

The results obtained in the PSB-E1 beam demonstrate that the shear strengthening technique is also very effective for increasing the shear capacity of already shear failed $\mathrm{RC}$ beams, since the highest values for the $F_{\max } / F_{\max }^{S B-C i}$ and $\Delta_{u} / \Delta_{u}^{S B-C i}$ of the total experimental program were registered in this beam, respectively, 2.77 and 4.72 .

The obtained results also indicate that bonding exclusively the RSFRM plates with epoxy adhesive was quite effective, since no great difference was verified in the shear capacity when mechanical bolts were also used. A possible justification can be the larger flexibility on the bond conditions between the RSFRM panels and concrete substrate when epoxy adhesive is used, which has allowed the panels to be in contact with the top and bottom flanges of the beam, mobilizing also the in-plane flexural capacity of these panels. By adding mechanical fasteners for fixing the RSFRM panels to the web of the RC beam, the stiffness of fixing conditions of the panels has increased. In consequence, the shear crack, which has the tendency to be initially formed in the web of the RC beam, has progressed through the panels almost exclusively restricted to the critical shear region.

However, more tests should be carried out in order to derive more reliable conclusions in this regard, mainly in beams submitted to fatigue loading conditions and/or exposure to 
high temperatures, since under these circumstances the epoxy-based bond performance can be altered, specifically if the beams can be simultaneously submitted to fatigue (creep effects of the adhesive (Costa and Barros 2015)), and wet-dry and temperature cycles (Mendes et al. 2014, Silva et al. 2016).

\section{Analytical approach for estimating the shear capacity of RC beams shear strengthened with RSFRM panels}

In this section the analytical formulation developed by Baghi et al. (2016), which is based on the Simplified Modified Compression Field Theory (SMCFT), was adapted in order to be applicable to the shear strengthening of RC beams with the developed RSFRM panels.

According to the approach proposed by Baghi et al. (2016), the shear capacity of a RC beam shear strengthened with panels $(v)$ is obtained from the following equation:

$$
v=v_{c}+v_{s}+v_{\text {panel }}
$$

where:

$$
\begin{aligned}
& v_{c}=\beta \cdot \sqrt{f_{c}^{\prime}} \\
& v_{s}=\rho_{s t} \cdot f_{s t, y} \cdot \cot \theta
\end{aligned}
$$

are the contribution due to concrete and steel stirrups for the shear capacity of a RC element, while $v_{\text {panel }}$ is the contribution of strengthening panels. Since the monitored shear span did not include steel stirrups, in the equation (4a) $v_{s}=0$.

In the SMCFT model suggested by Bentz et al. (2006), the shear strength of a section is a function of two parameters: the tensile stress factor in the cracked concrete $(\beta)$ (equation (5)), and the inclination of the diagonal compressive stress in the web of the section $(\theta)$ (equation (6)).

$$
\beta=\frac{0.4}{1+1500 \varepsilon_{s l}} \cdot \frac{1300}{1000+s_{x e}}
$$




$$
\theta=\left(29+700 \varepsilon_{s l}\right) \cdot\left(0.88+\frac{s_{x e}}{2500}\right) \leq 75^{\circ}
$$

In the equations (5) and (6) the $\varepsilon_{s l}$ is the axial strain of the longitudinal reinforcement evaluated at mid depth of the beam's cross section, while $s_{x e}$ is the crack spacing, which can be determined from the following equations:

$$
\begin{aligned}
& \varepsilon_{s l}=\frac{f_{s l}}{E_{s l}}=\frac{v \cot \theta-v_{c} / \cot \theta}{E_{s l} \rho_{s l}} \leq \varepsilon_{s l y} \\
& s_{x e}=\frac{35 S_{x}}{a_{g}+16} \geq 0.85 S_{x}
\end{aligned}
$$

where $S_{x}$ and $a_{g}$ represent, respectively, the vertical distance between longitudinal reinforcement (see Figure 21) and the maximum dimension of concrete aggregates. In Equations (7) and (8), $E_{s l}, \rho_{s l}$ and $\varepsilon_{s l y}$ are the modulus of elasticity, reinforcement ratio and yield strain of longitudinal reinforcement, respectively, where:

$$
\rho_{s l}=\frac{A_{s l}}{A_{c}}
$$

being $A_{c}$ the area of the concrete cross section, and $A_{s l}$ the cross-sectional area of the flexural reinforcement.

The maximum shear stress of a rectangular non-cracked cross section can be determined by the following equation (Blanksvärd 2009):

$$
\tau_{\max }=\frac{V Q}{I t}=\frac{3 V}{2 A}
$$

where $V$ is the total shear force and $A$ is the cross-sectional area. Shear resistance of the RSFRM panel can be determined from the following equation:

$$
V_{\text {panel }}=2\left(\frac{2}{3} t_{\text {panel }} h_{\text {panel }} \tau_{\text {avg }}\right)
$$


where perfect bond conditions between RSFRM panel and concrete substrate are assumed. In this equation $t_{\text {panel }}$ and $h_{\text {panel }}$ are the thickness and height of the RSFRM panel, respectively, while $\tau_{\text {avg }}$ is the crack shear stress, which is assumed as the value obtained from the inverse analysis with the data registered in the Iosipescu tests (3.8 MPa, see Table 3). Note that the factor 2 is justified by the use of one RSFRM panel in each lateral face of the beam. Accordingly, the shear capacity of a RC beam strengthened with RSFRM panels can be determined by equation (12) considering the contribution of strengthening panels and concrete in the shear capacity of the beam:

$$
v=v_{c}+v_{\text {panel }}=\beta \sqrt{f_{c}^{\prime}}+\frac{4 t_{\text {panel }} h_{\text {panel }} \tau_{\text {avg }}}{3\left(b_{w}+2 t_{\text {panel }}\right) d}
$$

where $b_{w}$ and $f_{c}^{\prime}$ are the width of the beam's cross section and concrete compressive strength, respectively. The solution procedure to calculate the shear strength of the concrete beams strengthened using RSFRM panel according to the SMCFT (Figure 22), has started by assuming the initial value of $1.0 \times 10^{-3}$ for $\varepsilon_{s l}$ (Bentz et al. 2006). Considering the maximum aggregate size $\left(a_{g}\right)$ was $19 \mathrm{~mm}$ in all beams and using for the $s_{x e}$ the value of $281 \mathrm{~mm}$ (equation (8)), the values of $\beta$ and $\theta$ are estimated equal to 0.1667 (equation (5)) and 35.25 degrees (equation 6), respectively, and a new value of $2.86 \times 10^{-4}$ is determined for $\varepsilon_{s l}$ (equation (7)). Since $2.86 \times 10^{-4}$ is not equal to the assumed value $\left(1.0 \times 10^{-3}\right)$, a new estimate of $\varepsilon_{s l}$ needs to be made and the calculations are repeated until convergence is reached (a tolerance of $10^{-6}$ was assumed for the absolute value of the difference between two consecutive $\varepsilon_{s l}$ values).

Finally, it should be checked if the longitudinal reinforcement can transmit the required stresses across the cracks without exceeding its yield stress. According to Bentz et al. (2006), the transmitted stress in the longitudinal reinforcement at cracked section $\left(f_{s l, c r}\right)$ is determined by:

$$
f_{s l, c r}=\frac{\left(v+v_{c}\right) \cot \theta}{\rho_{x}}
$$


Before evaluating the shear strength of the RC beams strengthened with RSFRM panels, the concrete compressive strength of the tested RC beams $\left(f_{c}^{\prime}\right)$ was derived by applying the intrinsic iterative procedure of the SMCFT to SB-C2 reference beam. For this purpose the shear capacity recorded experimentally in this beam (Table 4) was taken in equation (12) with $v_{\text {panel }}=0$, and a $f_{c}^{\prime}=42 \mathrm{MPa}$ was determined for an inclination of the shear failure crack $(\theta)$ of 35 degrees, which is quite close to the value verified experimentally (Figure 20d).

Table 5 includes the results of the tested beams in the second and third phases of the experimental program, as well as the values predicted according to the analytical formulations. Since the beams in the first phase have failed at support section before shear failure occurrence, these beams are not included in the analytical evaluation. The ratio between the experimental results and the analytical predictions in term of shear capacity is 1.09 with a COV of $6 \%$. The results in this table demonstrate the capability of this analytical approach to predict with good accuracy the ultimate shear capacity of RC beams strengthened or repaired with RSFRM panels. Table 5 shows that $f_{s l, c r}$ was less than the yield stress of the longitudinal reinforcement, therefore the longitudinal steel rebars are predicted do not yield at the cracked plane.

\section{Design Example}

This section aims to illustrate the design calculations of RSFRM panels for the shear strengthening of existing RC structures. For this purpose, the two-span T-cross section $\mathrm{RC}$ beam represented in Figure 23, of concrete strength class $\mathrm{C} 30 / 37\left(f_{c k}=30 M P a\right)$ reinforced with steel bars of strength class B400 ( $\left.f_{s y k}=400 \mathrm{MPa}\right)$ was considered. This beam was initially designed for a total design load of $q_{s d}=46 \mathrm{kN} / \mathrm{m}$, considered uniformly distributed in the beam, and due to alterations on the functionality of the pavements that this beam gives support, the new total design load is $q_{s d}=58 \mathrm{kN} / \mathrm{m}$.

The bending moment and shear force diagrams for the original and strengthening scenarios are represented in Figures 23 and 24. The steps resumes the design strategy for the structural strengthening intervention by using the RSFRM panels developed in this research project. 
Step 1: Compute the design material properties

The design value of the concrete compressive strength and yield strength of steel reinforcement are obtained according to Eurocode 2 recommendations:

$$
\begin{aligned}
& f_{c d}=\frac{f_{c k}}{\gamma_{c}}=\frac{30}{1.5}=20 \mathrm{MPa} \\
& f_{y d}=\frac{f_{y k}}{\gamma_{s}}=\frac{400}{1.15}=348 \mathrm{MPa}
\end{aligned}
$$

where $\gamma_{c}$ and $\gamma_{s}$ are the partial safety factors for concrete and steel reinforcement.

The design value of crack shear strength of RSFRM panel ( $\left.\tau_{R S F R M, R d}\right)$ is determined using equation (16), where the characteristic value of RSFRM panel $\left(\tau_{k}\right)$ was assumed as:

$$
\begin{gathered}
\tau_{R S F R M, R k}=0.7 \times \tau_{R S F R M, R m}=0.7 \times 3.8=2.66 \mathrm{MPa} . \\
\tau_{R S F R M, R d}=\frac{\tau_{R S F R M, R k}}{\gamma_{f}}=\frac{2.66}{1.5}=1.77 \mathrm{MPa}
\end{gathered}
$$

and adopting for the material safety factor, $\gamma_{f}$, the values proposed in the Model Code 2010 for fibre reinforced concrete.

Step 2: Calculate the flexural capacity

The design flexural strength of T-cross section type beam was determined by using the sectional analysis software DOCROS (Design Of CROss Sections) described elsewhere (Varma 2012). According to this software the cross section is decomposed in layers: a constitutive law can be attributed to the materials of the layers from a library of constitutive models for cement based material, metallic and polymer reinforcements, perfect bond conditions are assumed for the materials in contact, and a plane section before bending is considered plane after bending.

The design values of the positive and negative resisting bending moments of the critical sections of the beam were obtained from DOCROS (Figure 23): $M_{1, R d}^{+}=116 \mathrm{kN} . \mathrm{m}, M_{2, R d}^{-}$ $=232 \mathrm{kN} . \mathrm{m}$, and $M_{3, R d}^{+}=199 \mathrm{kN} . \mathrm{m}$, which demonstrates that the beam does not need any flexural strengthening intervention (Figure 24). 


\section{Step 3: Calculate the shear capacity}

The design shear strength of the beam's cross section is computed using the SMCFTbased analytical approach described in Section 4, considering the design strength value for the constituent materials. Accordingly, the design shear strength was determined equal to $178 \mathrm{kN}$, which is only exceeded in the central support zone (Figure 24), that will be shear strengthened with RSFRM panels.

\section{Step 4: Shear strengthening design}

For the shear strengthening purpose, a RSFRM panel of $900 \mathrm{~mm} \times 590 \mathrm{~mm} \times 25 \mathrm{~mm}$ is applied in each lateral face of the web's T-cross section of the beam in the zone where $V_{S d} \geq V_{R d}$. The design shear capacity of the strengthened section is determined using the described analytical model considering the design value of shear strength of RSFRM panel ( $\left.\tau_{R S F R M, R d}=1.77 \mathrm{MPa}\right)$, resulting a $V_{R d}=227 \mathrm{kN}$.

\section{Conclusions}

The first part of this work was dedicated to evaluate the mechanical properties of RSFRM, while the second part has assessed the benefits of thin panels of RSFRM for the shear strengthening of RC beams failing in shear. Based on the results presented in this work, the following concluding remarks can be highlighted:

- In the scope of inverse analysis for determining the fracture mode I parameters of RSFRM, higher values of tensile strength and fracture energy mode I were obtained from the simulation of the flexural tests compared to the values obtained from the simulation of the direct tensile tests. This was justified by different fibre pull-out mechanisms mobilized in the direct tensile and bending tests;

- The shear behaviour of the RSFRM was investigated by Iosipescu shear test method. It was verified that for the average sliding of $4.45 \mathrm{~mm}$, which is about 10 times the average sliding at peak load, the RSFRM is still capable of supporting $82 \%$ of the average shear strength, which confirms the high ductility and postcracking shear capacity of this cementitious composite when subjected to shear deformations;

- Based on the results in the second phase of the experimental program, it was verified that the RSFRM panels were capable of increasing significantly the load carrying (more than double the shear capacity of the corresponding reference RC 
beams) and deflection capacity of the tested RC beams. Furthermore, the obtained results have demonstrated the high effectiveness of RSFRM panels for the shear repairing of shear-damaged $\mathrm{RC}$ beams;

- The analytical formulation developed by Baghi et al. (2016), based on SMCFT, was adapted for the prediction of the shear capacity of RC beams strengthened with RSFRM panels, having been obtained an average value of 1.09 with a COV of $6 \%$ for $F_{\text {exp }} / F_{\text {ana }}$, indicating a high level of predicting accuracy.

At the end, a design example regarding the shear strengthening process of a two-span RC beam using RSFRM panels was provided.

\section{Acknowledgements}

The authors would acknowledge the contribution of CiviTest Company on the production of the specimens and $\mathrm{RC}$ beams, and on the execution of the experimental program of the RC beams. The authors wish also to acknowledge the support provided by BioSafe company on providing gratuity the RSF for the experimental program. The third author wish to acknowledge the grant SFRH/BSAB/114302/2016 provided by FCT. The support provided by the PTDC/ECM-EST/2635/2014 FCT project is also acknowledged.

\section{References}

ACI 318, (2008), "Building code requirements for structural concrete and commentary." appendix A, strut-and-tie models ed. s.l.: American Concrete Institute.

Aiello, M.A., Leuzzi F., Centonze G. \& Maffezzoli A. (2009), "Use of steel fibres recovered from waste tyres as reinforcement in concrete: Pull-out behaviour, compressive and flexural strength” Waste Management 29(6), pp:1960-1970.

Baghi, H. (2015), "Shear strengthening of reinforced concrete beams with SHCC-FRP panels" $\mathrm{PhD}$ thesis, University of Minho.

Baghi, H. \& Barros, J.A.O. (2016), "Shear Properties of the Strain Hardening Cementitious Composite Material" Journal of Materials in Civil Engineering. ISSN (online):1943-5533.

Baghi, H., Barros, J.A.O. \& Menkulasi, F. (2016), "Shear strengthening of reinforced concrete beams with Hybrid Composite Plates (HCP) technique: Experimental research and analytical model" Engineering Structures 125, pp:504-520. 
Barros, J.A.O. (2016), "Debilities and strengths of FEM-based constitutive models for the material nonlinear analysis of steel fiber reinforced concrete structures" 9th International Conference on Fracture Mechanics of Concrete and Concrete Structures, FraMCoS-9, V. Saouma, J. Bolander and E. Landis (Eds), California, May 29-June 1, 2016.

Barros, J.A.O., Baghi, H., Dias, S.J.E. \& Ventura-Gouveia, A. (2013), “A FEM-based model to predict the behaviour of RC beams shear strengthened according to the NSM technique", Engineering Structures Journal, 56, pp:1192-1206.

Barros, J.A.O., Lourenço, L. A., Soltanzadeh, F. \& Taheri, M. (2014), "Steel fibre reinforced concrete for elements failing in bending and in shear." European Journal of Environmental and Civil Engineering, 18(1), pp:33-65.

Bentz, E.C., Vecchio, F.J. \& Collins, M.P. (2006), “Simplified modified compression field theory for calculating shear strength of reinforced concrete elements" ACI Struct Journal, 103(4), pp:614-624.

Blanksvärd, T. (2009), "Strengthening of concrete structures by the use of mineral based composites.” PhD Thesis. Luleå University of Technology.

CEB-fib Model Code 2010, CEB and FIP, 2011

Collins, M.P. and Mitchell, D. (1991), "Prestressed concrete structures", New Jersey:Prentice-Hall.

Costa, I.G. \& Barros, J.A.O. (2015), "Tensile creep of a structural epoxy adhesive: experimental and analytical characterization" International Journal of Adhesion \& Adhesives, 59, pp:115-124.

Cunha, V.M.C.F., Barros, J.A.O. \& Sena-Cruz, J.M. (2010), "Pullout Behaviour of Steel Fibres in Self-Compacting Concrete." Journal of Materials in Civil Engineering, 22(1), pp:1-9.

Domski, J., Katzer, J., Zakrzewski, M., Ponikiewski, T. (2017), “Comparison of the mechanical characteristics of engineered and waste steel fiber used as reinforcement for concrete." Journal of Cleaner Production, 158, pp:18-28.

EN 10002-1:1990. Metallic materials-Tensile testing. Part 1: Method of test (at ambient temperature). CEN, Brussels, Belgium, 35.

Eurocode 2, (2004), Design of concrete structures - Part 1-1: General rules and rules for buildings. Brussels: Comité Européen de Normalisation (CEN), EN 1992-1$1: 2004$. 
Graeff, A.G., Pilakoutas, K., Neocleous, K. \& Vania N.N. Peres, M. (2012), “Fatigue resistance and cracking mechanism of concrete pavements reinforced with recycled steel fibres recovered from post-consumer tyres" Engineering Structures, 45, pp:385-395.

Kuchma, D.A.M., Hawkins, N., Kim, S., Sun, S., and Su Kim, K. (2008). "Simplified shear provisions of the AASHTO LRFD Bridge Design Specifications." PCI Journal, pp:53-73.

Leung, C.K.Y. \& Geng, Y.P. (1998), "Micromechanical modeling of softening behaviour in steel fibre reinforced cementicious composites." Int. Journal Solids Strucutres, 35(32), pp:4205-4222.

Leung, C.K.Y. \& Shapiro, N. (1999) “Optimal steel fibre strength for reinforcement of cementitious materials," Journal of Materials in Civil Engineering, 11(2) pp:116123.

Li, V.C. (1998) "Engineered Cementitious Composites for Structural Applications." Materials in Civil Engineering 10, pp:66-69.

LNEC E397-1993:1993. Concrete - Determination of the elasticity young modulus under compression. Portuguese specification from LNEC

Mendes, P.J.D., Barros, J.A.O., Sena-Cruz, J.M. \& Taheri, M., (2014), “Influence of fatigue and aggressive exposure on GFRP girder to SFRC deck all-adhesive connection”, Composite Structures Journal, 110, pp:152-162.

Neocleous, K., Tlemat, H. \& Pilakoutas, K., (2006), "Design Issues for Concrete Reinforced with Steel Fibres, Including Fibres Recovered from Used Tyres." Materials in Civil engineering, 18(5), pp:677-685.

NP EN 12390-3:2011. Testing hardened concrete. Part 3: Compressive strength of test specimens.

NZS4203, (1992), General structural design and design loadings for buildings, standard published 12/14/1992 by Standards New Zealand.

Pereira, E.N.B., Fischer, G. \& Barros, J.A.O., (2012), “Direct assessment of tensile stresscrack opening behavior of Strain Hardening Cementitious Composites (SHCC)”, Cement and concrete Research, 42, pp:834-846.

Silva, P., Fernandes, P., Sena-Cruz, J., Xavier, J., Castro, F., Soares, D. \& Carneiro, V. (2016), "Effects of different environmental conditions on the mechanical characteristics of a structural epoxy.” Composites Part B, 88, pp:55-63. 
Varma, R.K. (2012) "Numerical Models for the Simulation of the Cyclic Behaviour of $R C$ ”, $\mathrm{PhD}$ thesis, University of Minho.

Ventura-Gouveia, A., (2011), “Constitutive models for the material nonlinear analysis of concrete structures including time dependent effects". $\mathrm{PhD}$ Thesis, Department of Civil Engineering, University of Minho.

Zamanzadeh, Z., Lourenço, L.A.P. \& Barros, J.A.O. (2015)a, "Recycled steel fibre reinforced concrete failing in bending and in shear" Journal of Construction and Building Materials. 85, pp:195-207.

Zamanzadeh, Z., Lourenço, L.A.P. \& Barros, J.A.O. (2015)b, “Thin panels of cement composites reinforced with recycled fibres for the shear strengthening of reinforced concrete elements" $8^{\text {th }}$ International conference FIBRE CONCRETE, Prague Czech Republic. 


\section{Table captions}

Table 1- Mix compositions

Table 2 - Values defining the tensile softening diagram obtained from inverse analysis Table 3 - Values of the parameters of the RSFRM constitutive model

Table 4 - Relevant results in terms of maximum load capacity and corresponding mid span deflection

Table 5 - Analytical vs. experimental results of the strengthened beams with RSFRM panels 
Table 1- Mix compositions

\begin{tabular}{ccccccc}
\hline $\begin{array}{c}\text { C } \\
{\left[\mathbf{k g} / \mathbf{m}^{3}\right]}\end{array}$ & $\begin{array}{c}\text { FA } \\
{\left[\mathbf{k g} / \mathbf{m}^{3}\right]}\end{array}$ & $\begin{array}{c}\text { FS } \\
{\left[\mathbf{k g} / \mathbf{m}^{3}\right]}\end{array}$ & $\begin{array}{c}\text { VMA } \\
{\left[\mathbf{k g} / \mathbf{m}^{3}\right]}\end{array}$ & $\begin{array}{c}\text { SP } \\
{\left[\mathbf{k g} / \mathbf{m}^{3}\right]}\end{array}$ & $\begin{array}{c}\text { W } \\
{\left[1 / \mathbf{m}^{3}\right]}\end{array}$ & $\begin{array}{c}\text { W/C } \\
{[\mathbf{l} / \mathbf{k g}]}\end{array}$ \\
\hline 546 & 669 & 437 & 1.710 & 11 & 318 & 0.58
\end{tabular}

$\mathrm{C}=$ Cement; FA = Fly Ash; FS = Fine Sand; VMA = Viscosity modifying admixture; SP = Superplasticizer; $\mathrm{W}=\mathrm{W}$ ater; $\mathrm{W} / \mathrm{C}=$ Water-Cement ratio. 
Table 2 - Values defining the tensile softening diagram obtained from inverse analysis

\begin{tabular}{|c|c|c|c|c|c|c|}
\hline Series & $\begin{array}{c}\sigma_{n, 1}^{c r} \\
{\left[\mathrm{~N} / \mathbf{m m}^{2}\right]}\end{array}$ & & & & $\sigma_{n, 3}^{c r} / \sigma_{n, 1}^{c r}$ & $\begin{array}{c}\boldsymbol{G}_{\boldsymbol{f}}^{\boldsymbol{I}} \\
{[\mathrm{N} / \mathrm{mm}]}\end{array}$ \\
\hline Bending test & 3.000 & 0.070 & 1.200 & 0.600 & 1.130 & 12.000 \\
\hline Tensile test & 2.450 & 0.004 & 1.390 & 0.019 & 0.700 & 8.000 \\
\hline
\end{tabular}


Table 3 - Values of the parameters of the RSFRM constitutive model

\begin{tabular}{ll}
\hline Property & Value \\
\hline Poisson's ratio & 0.19 \\
\hline Compressive strength & $46.64 \mathrm{~N} / \mathrm{mm}^{2}$ \\
\hline Young's modulus & $19640 \mathrm{~N} / \mathrm{mm}^{2}$ \\
\hline $\begin{array}{l}\text { Tri-linear tension softening diagram of } \\
\text { RSFRM }\end{array}$ & $\begin{array}{l}\text { The same obtained from inverse analysis with the } \\
\text { direct tensile test results (see Table 3) }\end{array}$ \\
\hline $\begin{array}{l}\text { Parameter defining the mode I fracture } \\
\text { energy available for the new crack }\end{array}$ & $P_{2}=3$ \\
\hline Crack shear softening diagram & $\sigma_{t, p}^{c r}=3.8 \mathrm{~N} / \mathrm{mm}^{2}, G_{f s}=3.3 \mathrm{~N} / \mathrm{mm}, \beta=0.5$ \\
\hline Crack band width & $\begin{array}{l}\text { Square root of the area of Gauss } \\
\text { integration point }\end{array}$ \\
\hline Threshold angle & $\alpha_{t h}=30^{\circ}$ \\
\hline
\end{tabular}


Table 4 - Relevant results in terms of maximum load capacity and corresponding mid span deflection

\begin{tabular}{ccccc}
\hline $\begin{array}{c}\text { Beam } \\
\text { designation }\end{array}$ & $\begin{array}{c}\text { Mid span } \\
\text { deflection } \\
{[\mathbf{m m}]}\end{array}$ & $\boldsymbol{F}_{\boldsymbol{m a x}}[\mathrm{kN}]$ & $\frac{\Delta_{u}}{\Delta_{u}^{S B-C i}}$ & $\frac{\boldsymbol{F}_{\text {max }}}{\boldsymbol{F}_{\text {max }}^{S B-C i}}$ \\
\hline SB-C1 & 0.36 & 69.10 & - & - \\
SB-E1 & 1.22 & 143.18 & 3.40 & 2.07 \\
SB-EM1 & 1.32 & 176.50 & 3.66 & 2.55 \\
SB-C2 & 0.63 & 82.54 & - & - \\
SB-E2 & 2.38 & 197.34 & 3.77 & 2.39 \\
SB-EM2 & 1.93 & 187.50 & 3.06 & 2.27 \\
PSB-E1 & 1.70 & 191.75 & 4.72 & 2.77 \\
\hline
\end{tabular}


Table 5 - Analytical vs. experimental results of the strengthened beams with RSFRM panels

\begin{tabular}{cccccc}
\hline Specimen & $\boldsymbol{\varepsilon}_{\text {sl }}[\% \mathbf{\%}]$ & $\boldsymbol{F}_{\text {exp }}[\mathbf{k N}]$ & $\boldsymbol{F}_{\text {ana }}[\mathbf{k N}]$ & $\boldsymbol{f}_{\text {sl, } \boldsymbol{c r}}[\mathbf{M P a}]$ & $\boldsymbol{F}_{\text {exp }} / \boldsymbol{F}_{\text {ana }}$ \\
\hline SB-C2 & 0.08 & 83 & 83 & 104 & 1.00 \\
SB-E2 & 0.29 & 197 & 172 & 188 & 1.14 \\
SB-EM2 & 0.29 & 188 & 172 & 188 & 1.09 \\
PSB-E1 & 0.29 & 192 & 172 & 188 & 1.12 \\
& & & & Ave & 1.09 \\
& & & & COV & $6 \%$ \\
\hline
\end{tabular}




\section{Figure captions}

Figure 1. Recycled steel fibres extracted from post consumed tyres

Figure 2. The technique used for producing RSFRM panels

Figure 3. Test setup for three point bending test using (width of the cross section is 50 $\mathrm{mm}$ ): a) un-notched specimens and b) notched specimens_(dimensions in $\mathrm{mm}$ )

Figure 4. The envelope and the average curve of the flexural stress vs. CMOD of the notched specimens

Figure 5. Assessment of the tensile properties of RSFRM: a) Extraction configuration from RSFRM panel; b) Tensile specimens geometry and dimensions in mm; c) Test setup for RDTT0 and RDTT45 specimens; d) Test setup for DBDTT specimens_(dimensions in $\mathrm{mm})$

Figure 6. a) Crack patterns from initiation to failure (RDTT0 specimen), b) Stress-strain diagrams obtained from direct tensile tests

Figure 7. Concept of Iosipescu shear test (Baghi 2015)

Figure 8. Iosipescu testing program: a) used device, b) specimen's geometry (dimensions in $\mathrm{mm}$ ) and c) the position of the LVDT to measure sliding of the shear crack at notched section

Figure 9. a) The envelope and average stress $v s$. crack sliding, and b) Typical crack patterns of tested Iosipescu specimens

Figure 10. Trilinear stress-strain diagram to simulate the fracture mode I crack propagation $\left(\sigma_{n, 2}^{c r}=\alpha_{1} \sigma_{n, 1}^{c r}, \sigma_{n, 3}^{c r}=\alpha_{2} \sigma_{n, 1}^{c r}, \varepsilon_{n, 2}^{c r}=\xi_{1} \varepsilon_{n, u}^{c r}, \varepsilon_{n, 3}^{c r}=\xi_{2} \varepsilon_{n, u}^{c r}\right)$.

Figure 11. Finite element mesh, support and loading conditions adopted in the inverse analysis: a) notched beam bending test, and b) direct tensile test (dimensions in $\mathrm{mm}$ )

Figure 12. Inverse analysis applied to: a) notched beam bending tests; and b) direct tensile test

Figure 13. Bending and shear forces introduced in an inclined fibre bridging a crack during its pull-out process (based on Leung and Geng 1998)

Figure 14. Finite element mesh of the Iosipescu specimen

Figure 15. Comparison between experimental and numerical shear stress $v s$. sliding relationship

Figure 16. Test setup and position of the LVDTs in the experimental program for the assessment of the shear strengthening effectiveness of RSFRM panels for RC beams (dimensions in $\mathrm{mm}$ )

Figure 17. Strengthening methods: a) SB-E beams fixed only with epoxy; b) SB-EM beams fixed with epoxy and mechanical fasteners (dimensions in $\mathrm{mm}$ )

Figure 18. Confinement system applied to the support regions of the RC beams

Figure 19. Load - deflection relationship at the loaded section for the tested RC beams in the: a) First; b) Second; and c) Third experimental program

Figure 20. Crack pattern at failure of the tested beams: a) SB-C1, b) SB-E1, c) SB-EM1, d) SB-C2, e) SB-E2, f) SB-EM2, g) PSB-E1

Figure 21. Concept of $S_{x}$ (Collins and Mitchell 1991)

Figure 22. Calculation procedure of SMCFT adapted for the strengthening technique with RSFRM panels 
Figure 23. Geometry, loading configuration, and flexural bending moment and shear diagrams of two-span T-cross section RC beam

Figure 24. Strengthening geometry, increased live load, and flexural bending moment and shear diagrams of two-span T-cross section RC beam 


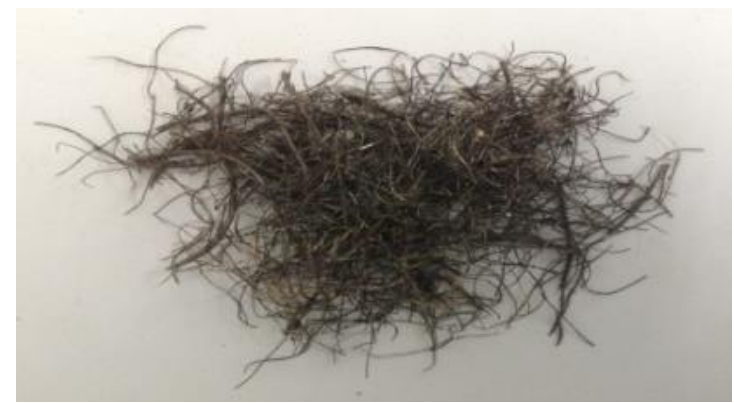

Figure 1. Recycled steel fibres extracted from post consumed tyres 

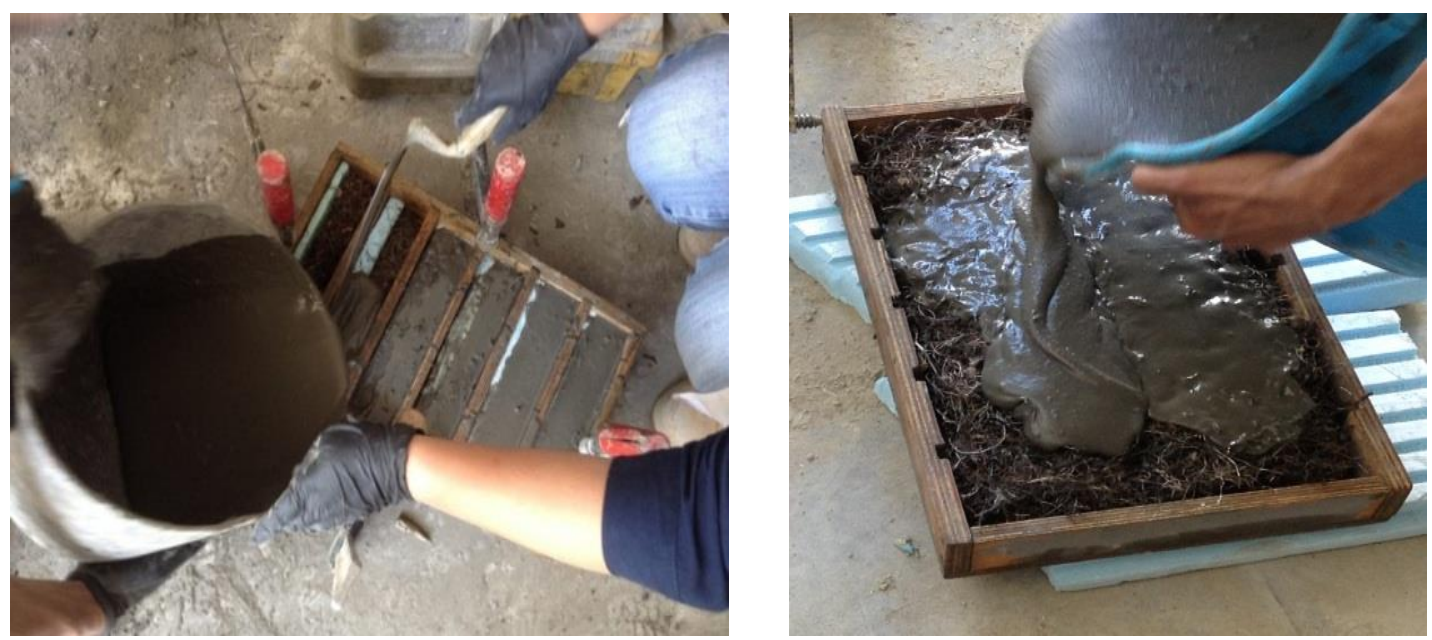

Figure 2. The technique used for producing RSFRM panels 


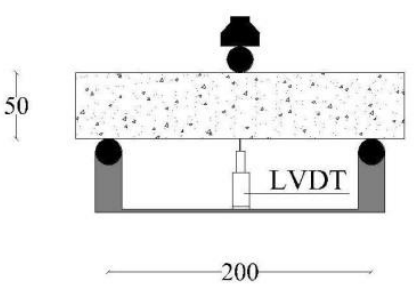

a)

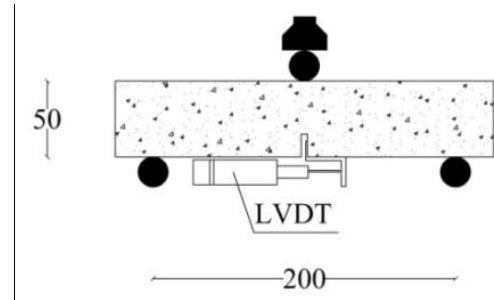

b)

Figure 3. Test setup for three point bending test using (width of the cross section is 50 $\mathrm{mm}$ ): a) un-notched specimens and b) notched specimens (dimensions in $\mathrm{mm}$ ) 


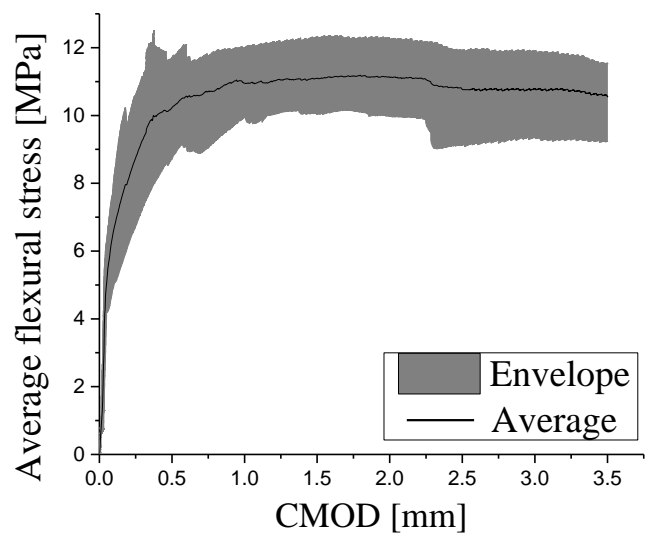

Figure 4. The envelope and the average curve of the flexural stress $v s$. CMOD of the notched specimens 


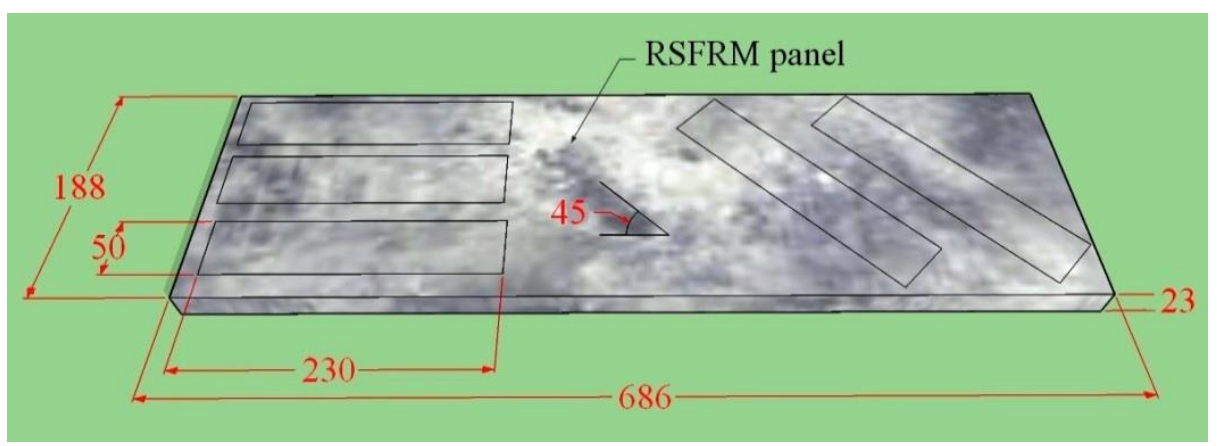

a)
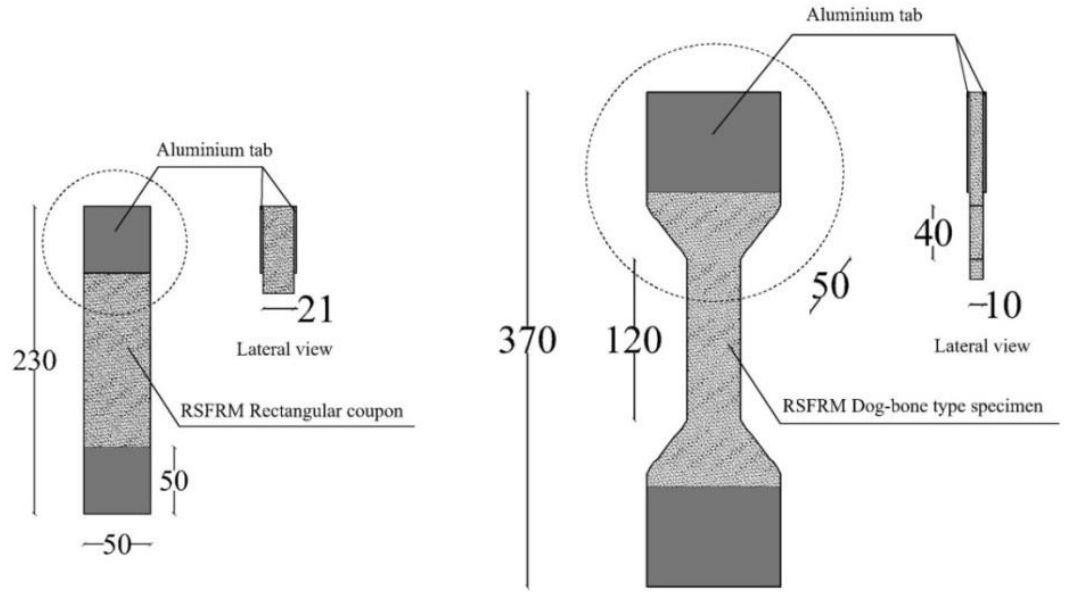

$-40$

$-100-$

b)

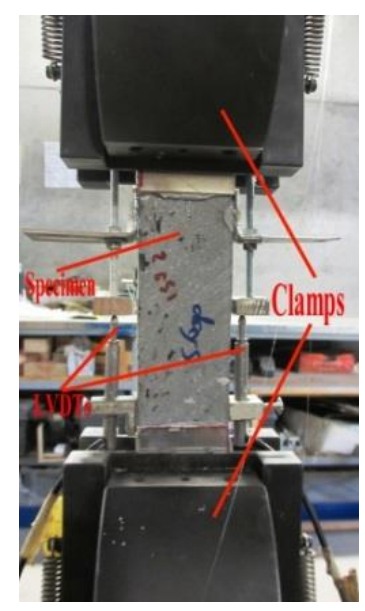

c)

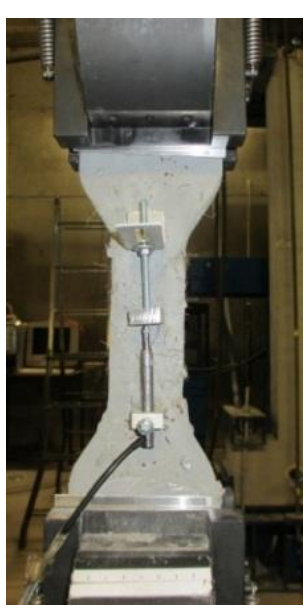

d)

Figure 5. Assessment of the tensile properties of RSFRM: a) Extraction configuration from RSFRM panel; b) Tensile specimens geometry and dimensions in mm; c) Test setup for RDTT0 and RDTT45 specimens; d) Test setup for DBDTT specimens (dimensions in $\mathrm{mm})$ 


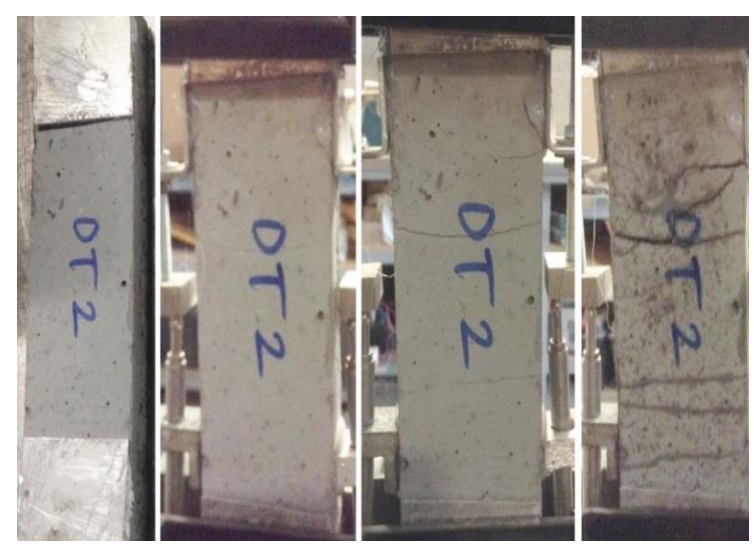

a)

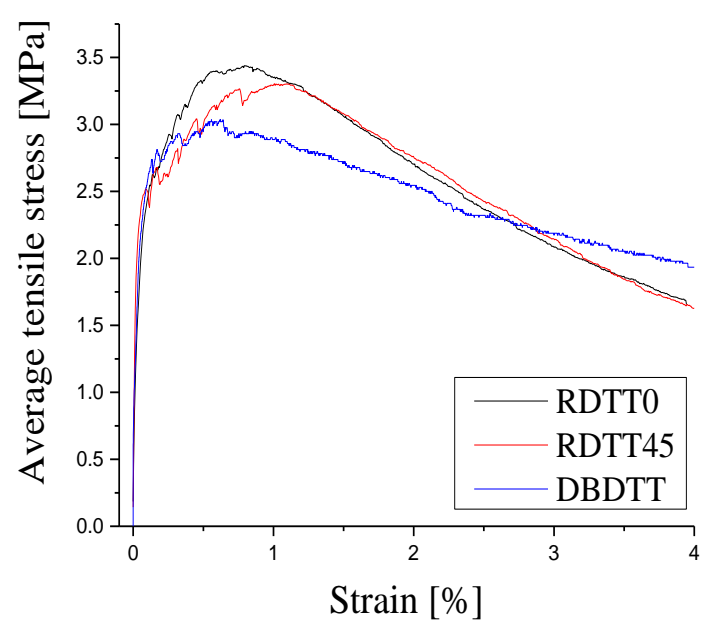

b)

Figure 6. a) Crack patterns from initiation to failure (RDTT0 specimen), b) Stress-strain diagrams obtained from direct tensile tests 


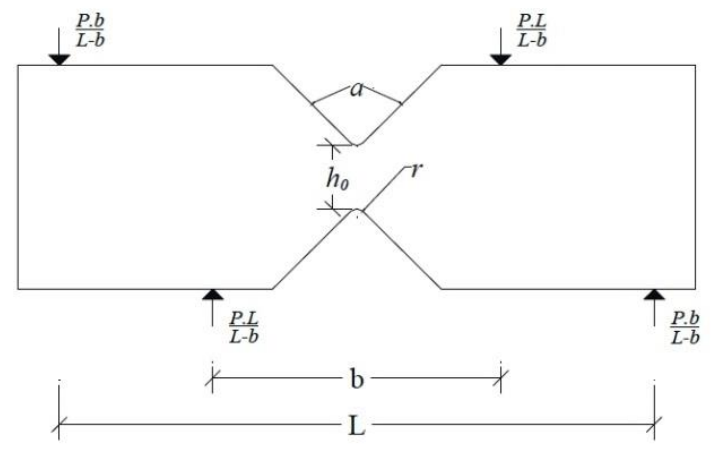

Figure 7. Concept of Iosipescu shear test (Baghi 2015) 


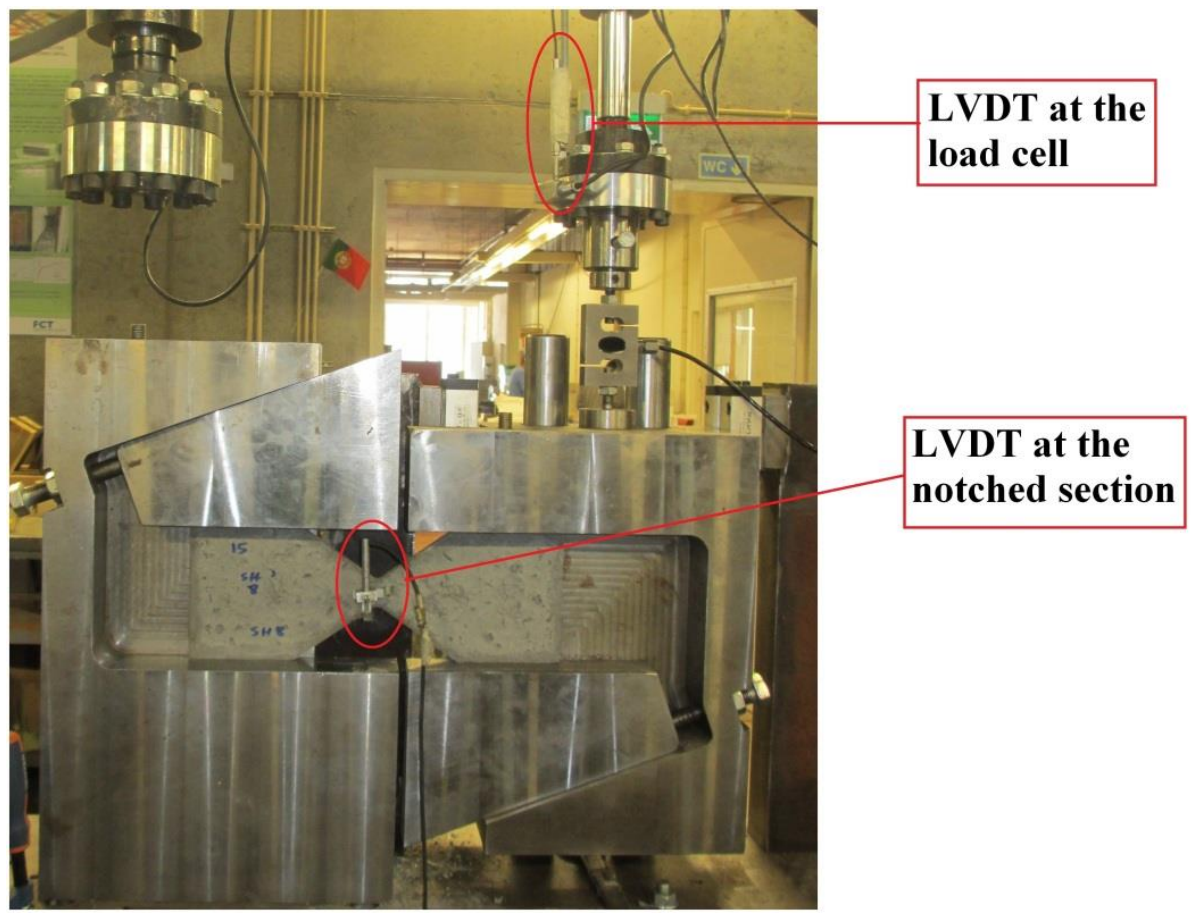

a)

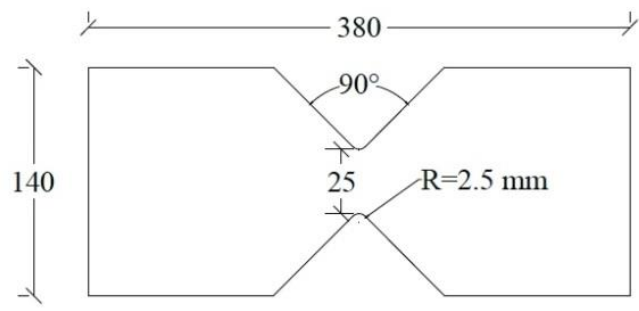

b)

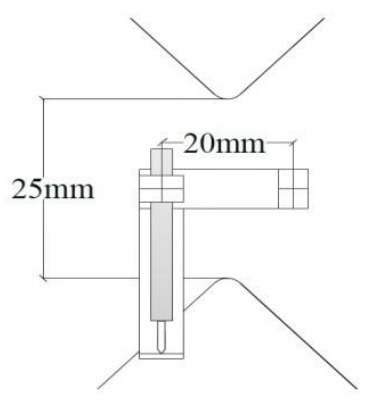

c)

Figure 8. Iosipescu testing program: a) used device, b) specimen's geometry (dimensions in $\mathrm{mm}$ ) and c) the position of the LVDT to measure sliding of the shear crack at notched section 


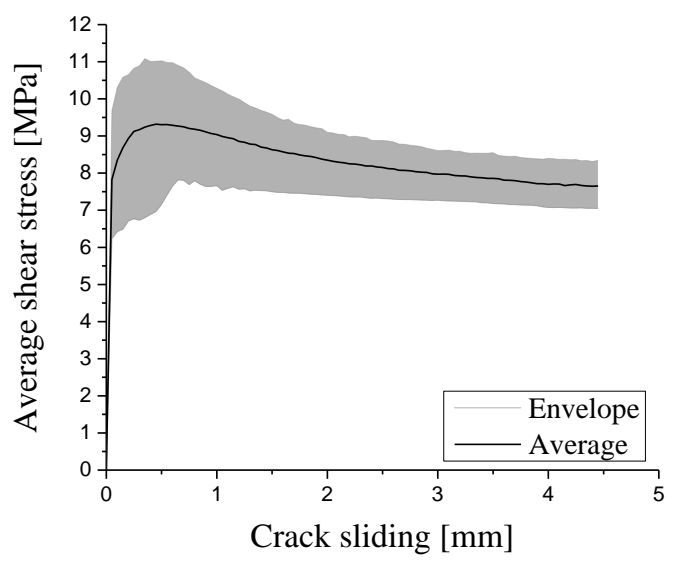

a)

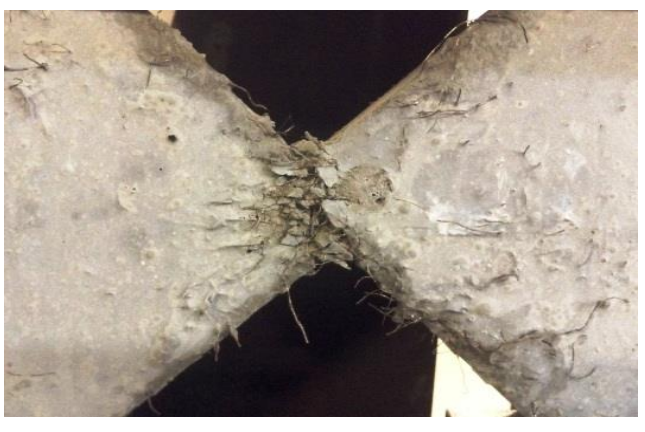

b)

Figure 9. a) The envelope and average stress $v s$. crack sliding, and b) Typical crack patterns of tested Iosipescu specimens 


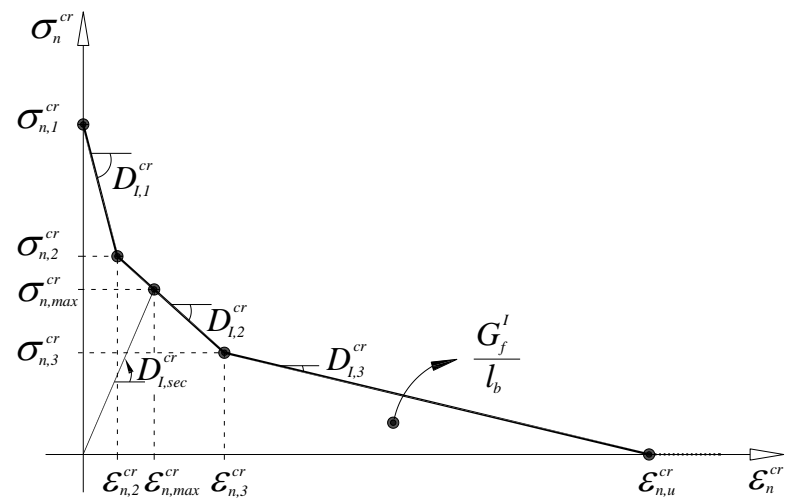

Figure 3. Trilinear stress-strain diagram to simulate the fracture mode I crack propagation $\left(\sigma_{n, 2}^{c r}=\alpha_{1} \sigma_{n, 1}^{c r}, \sigma_{n, 3}^{c r}=\alpha_{2} \sigma_{n, 1}^{c r}, \varepsilon_{n, 2}^{c r}=\xi_{1} \varepsilon_{n, u}^{c r}, \varepsilon_{n, 3}^{c r}=\xi_{2} \varepsilon_{n, u}^{c r}\right)$. 


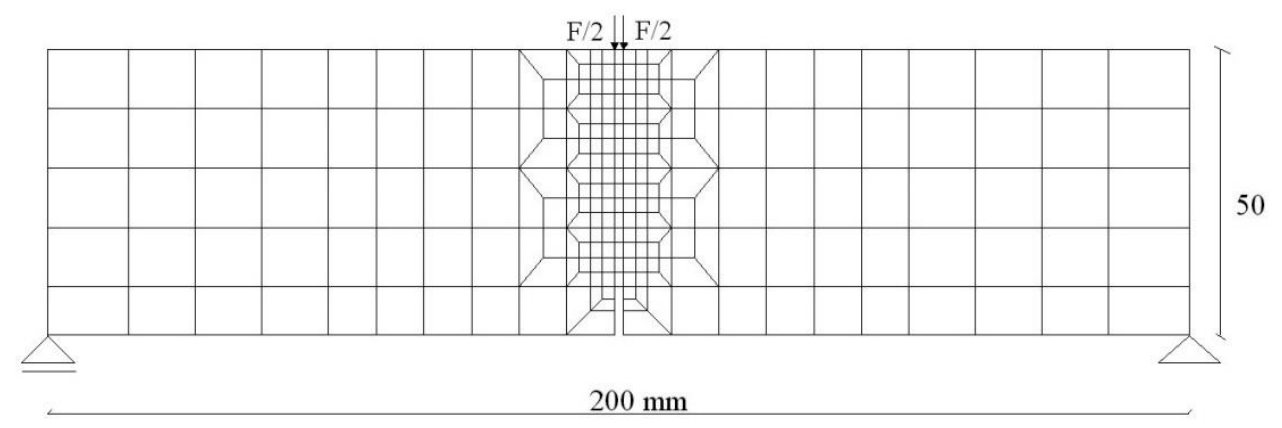

a)

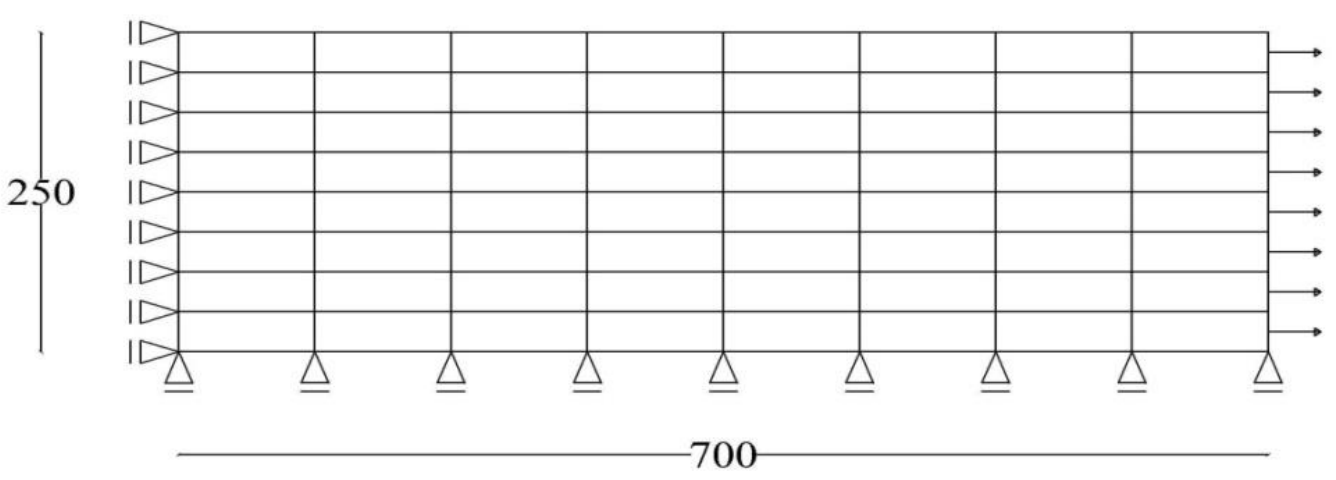

b)

Figure 4. Finite element mesh, support and loading conditions adopted in the inverse analysis: a) notched beam bending test, and b) direct tensile test (dimensions in $\mathrm{mm}$ ) 


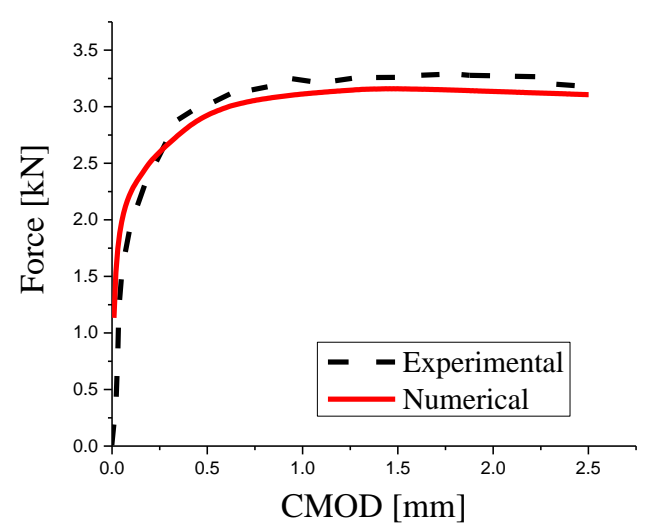

a)

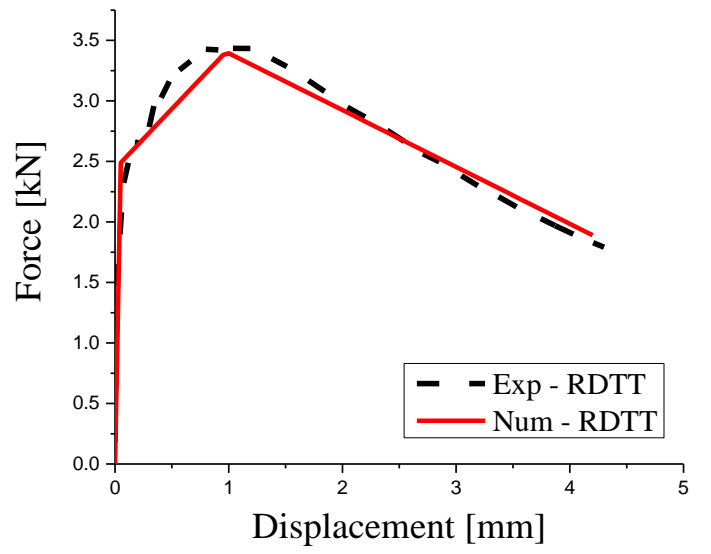

b)

Figure 5. Inverse analysis applied to: a) notched beam bending tests; and b) direct tensile test 


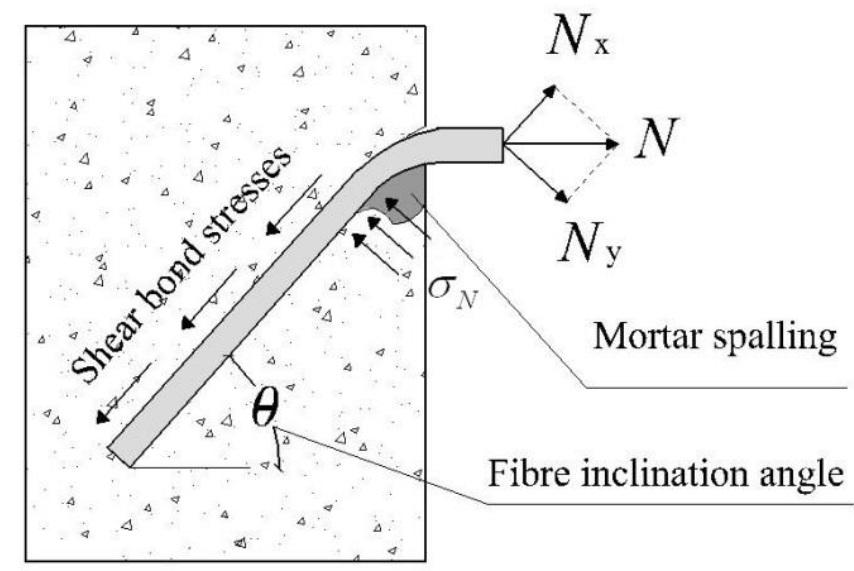

Figure 6. Bending and shear forces introduced in an inclined fibre bridging a crack during its pull-out process (based on Leung and Geng 1998) 


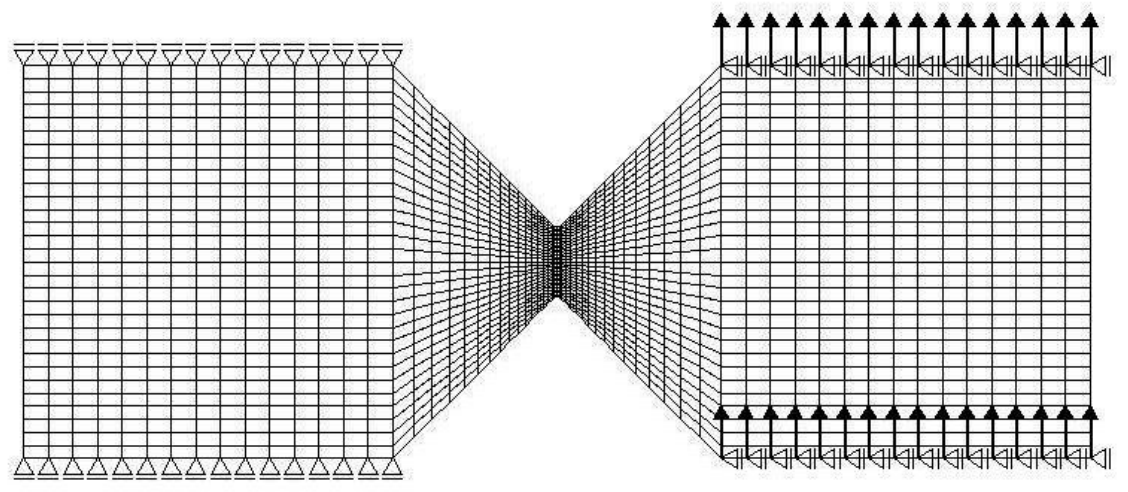

Figure 7. Finite element mesh of the Iosipescu specimen 


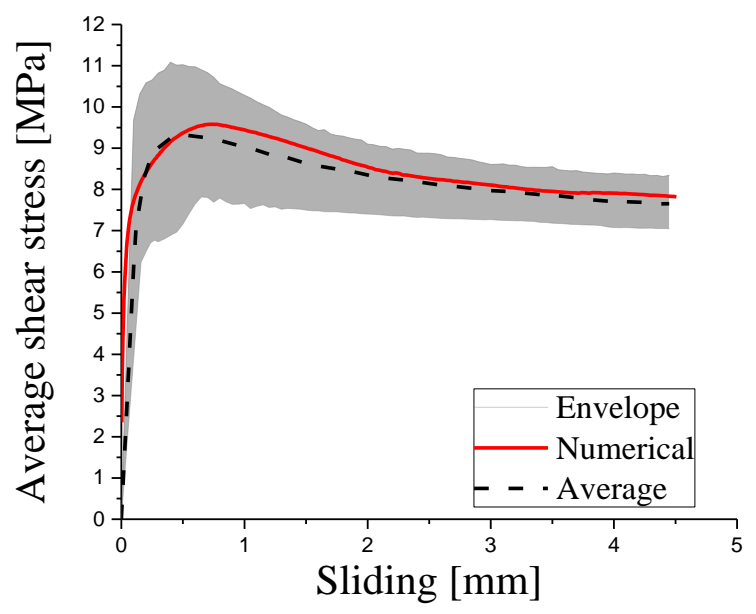

Figure 8. Comparison between experimental and numerical shear stress vs. sliding relationship 

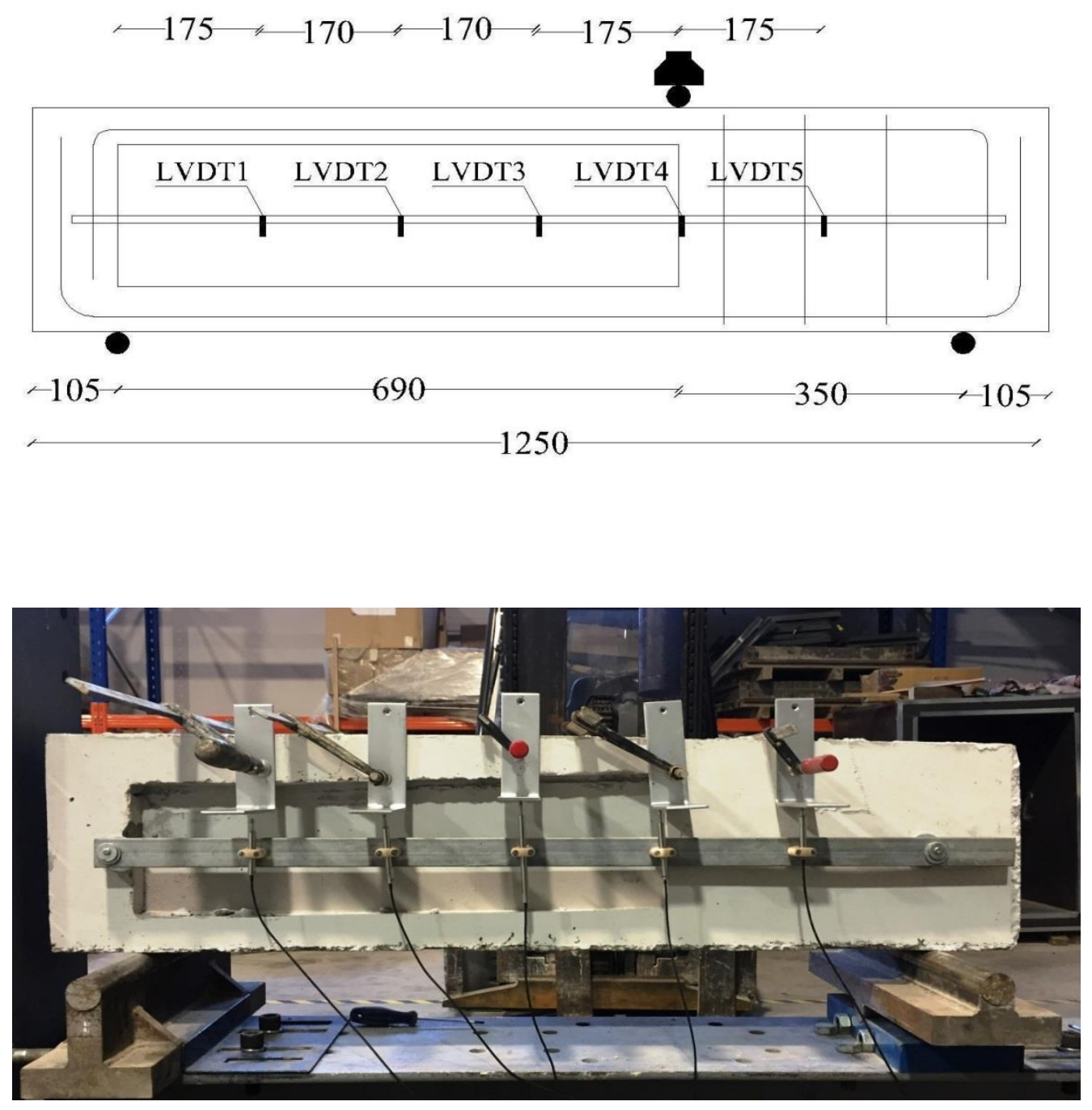

Figure 9. Test setup and position of the LVDTs in the experimental program for the assessment of the shear strengthening effectiveness of RSFRM panels for RC beams (dimensions in $\mathrm{mm})$ 

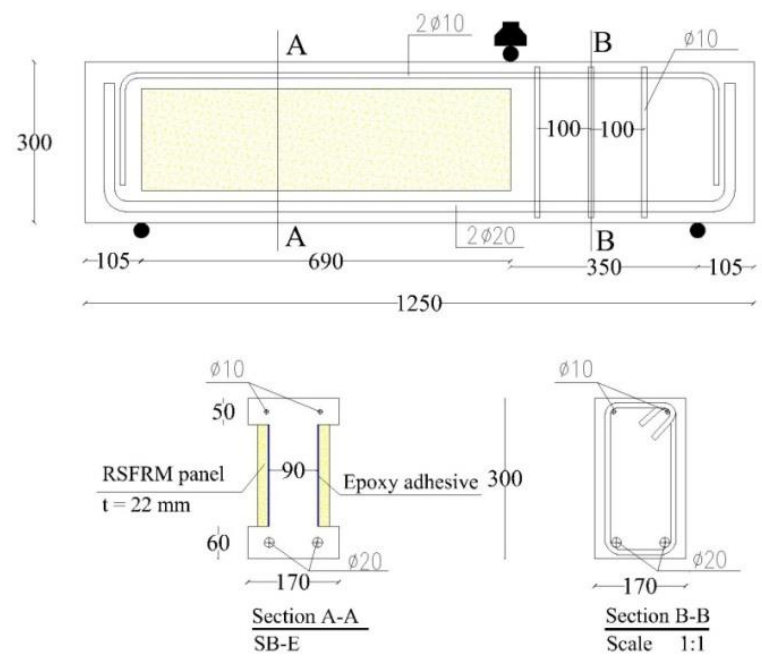

a)
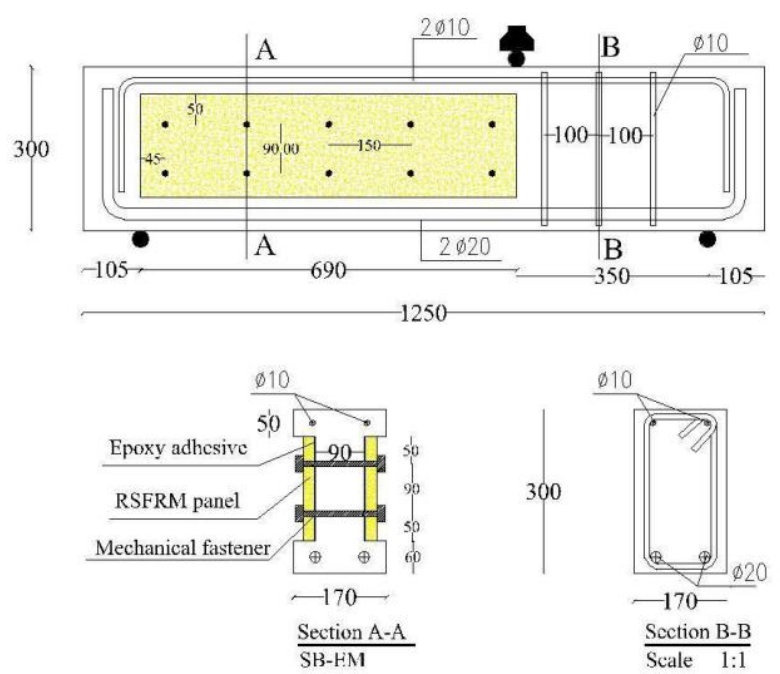

b)

Figure 10. Strengthening methods: a) SB-E beams fixed only with epoxy; b) SB-EM beams fixed with epoxy and mechanical fasteners (dimensions in $\mathrm{mm}$ ) 

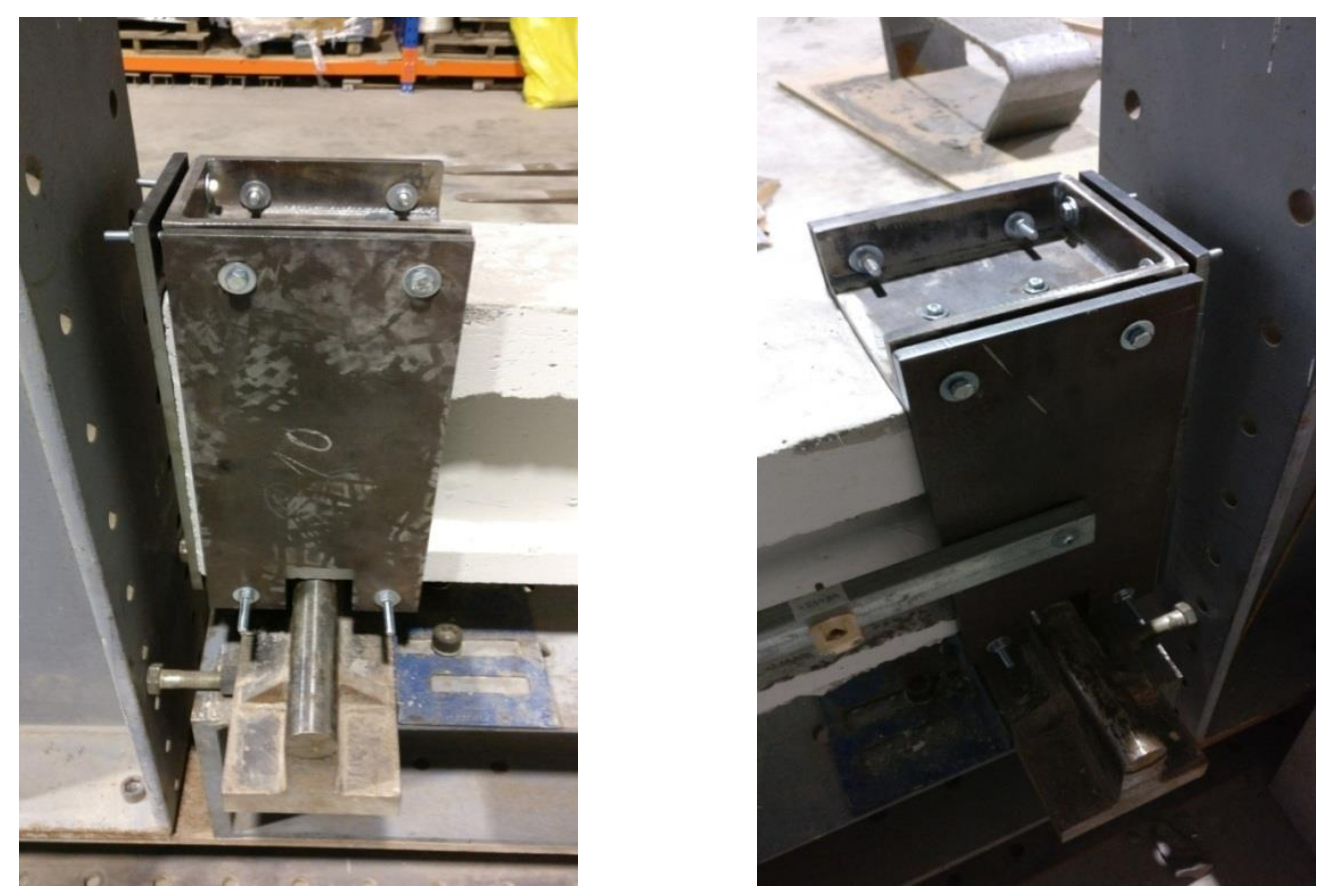

Figure 11. Confinement system applied to the support regions of the RC beams 


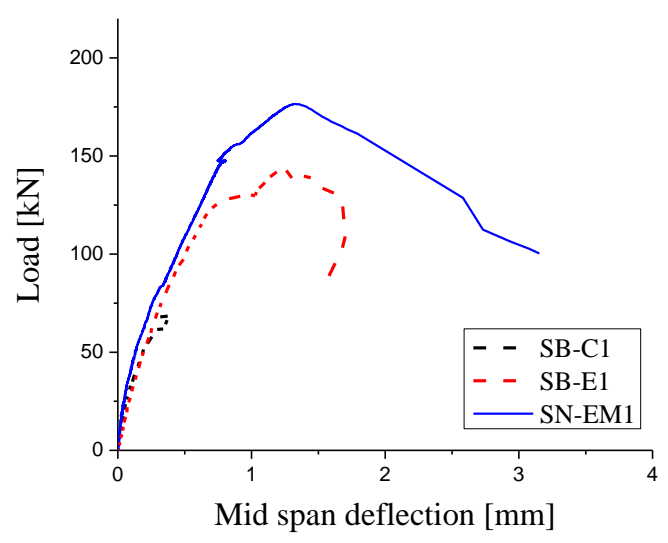

a)

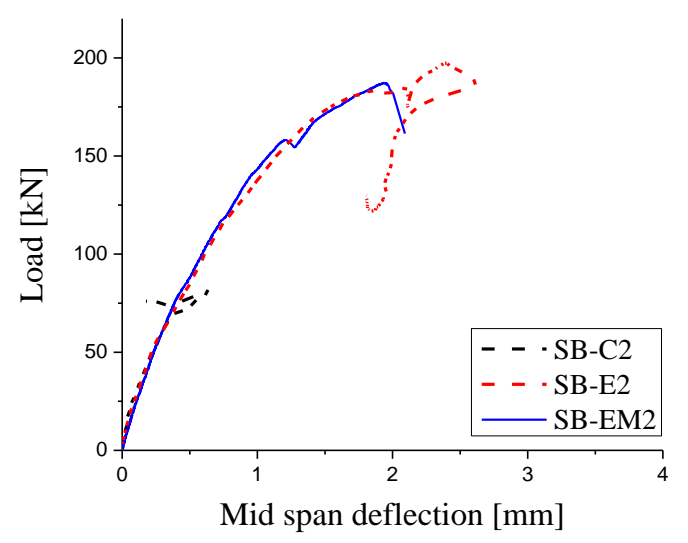

b)

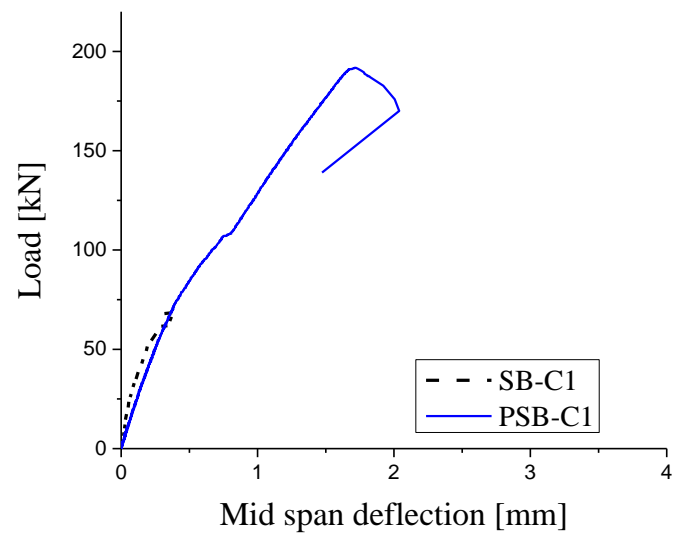

c)

Figure 19. Load - deflection relationship at the loaded section for the tested RC beams in the: a) First; b) Second; and c) Third experimental program 


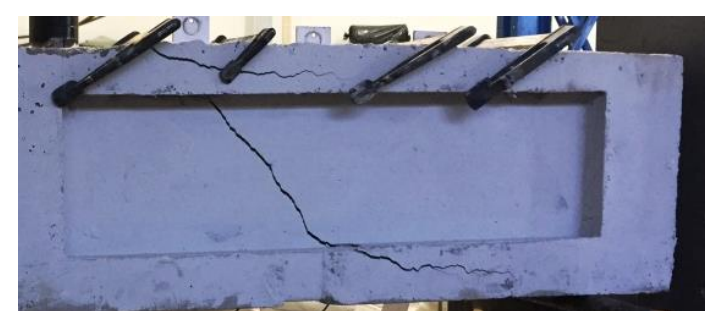

a)

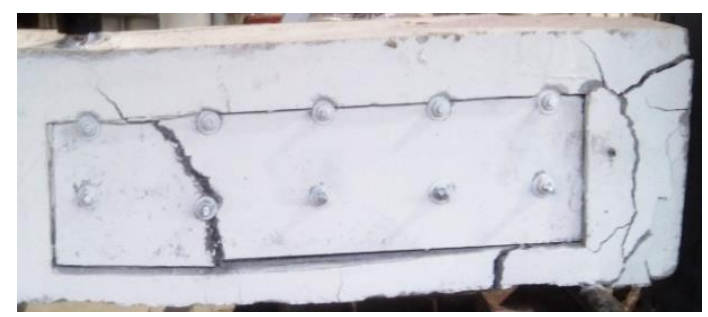

c)

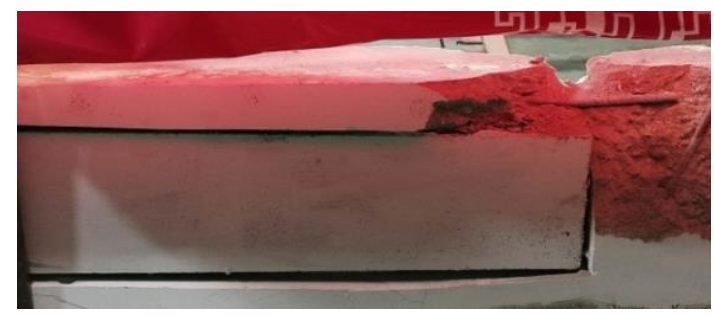

e)

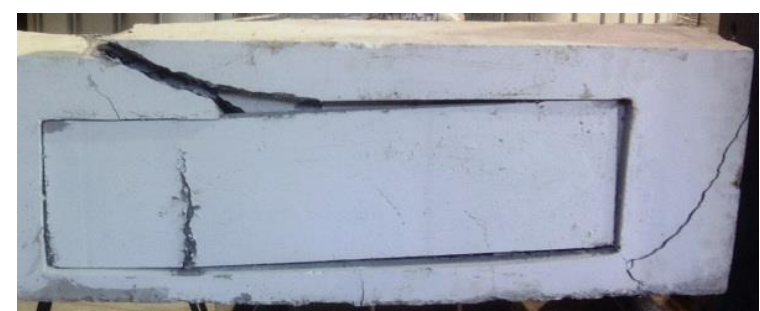

b)

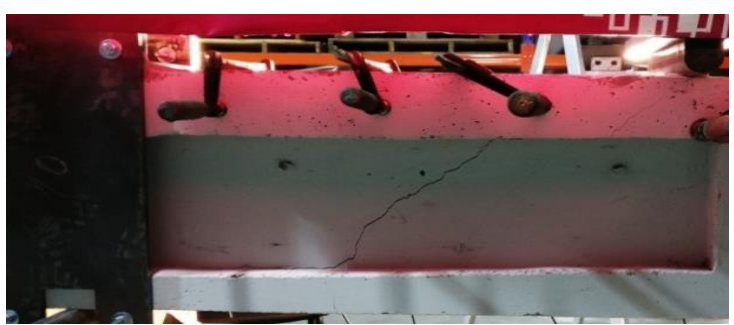

d)

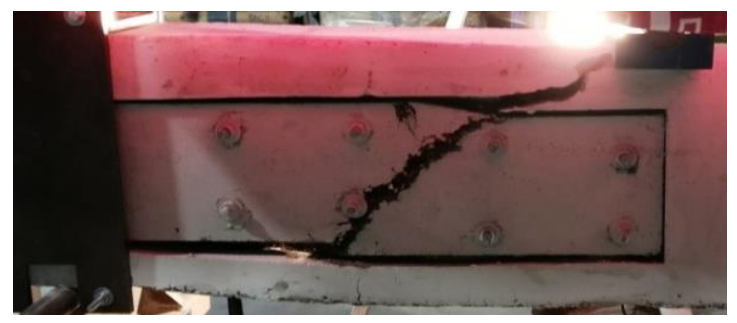

f)

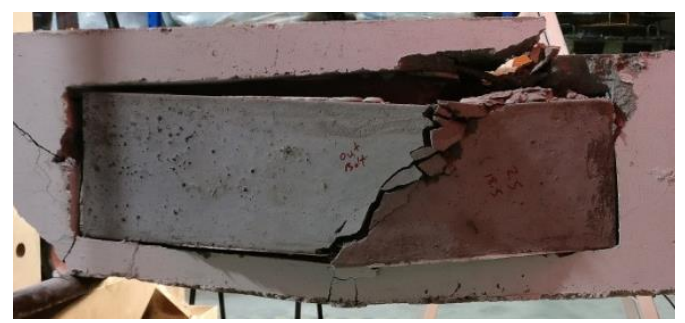

g)

Figure 12. Crack pattern at failure of the tested beams: a) SB-C1, b) SB-E1, c) SB-EM1, d) SB-C2, e) SB-E2, f) SB-EM2, g) PSB-E1 


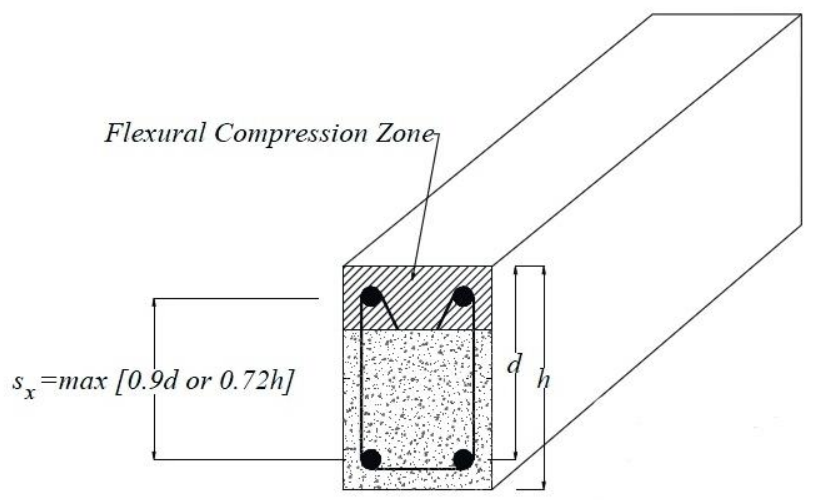

Figure 13. Concept of $S_{x}$ (Collins and Mitchell 1991) 


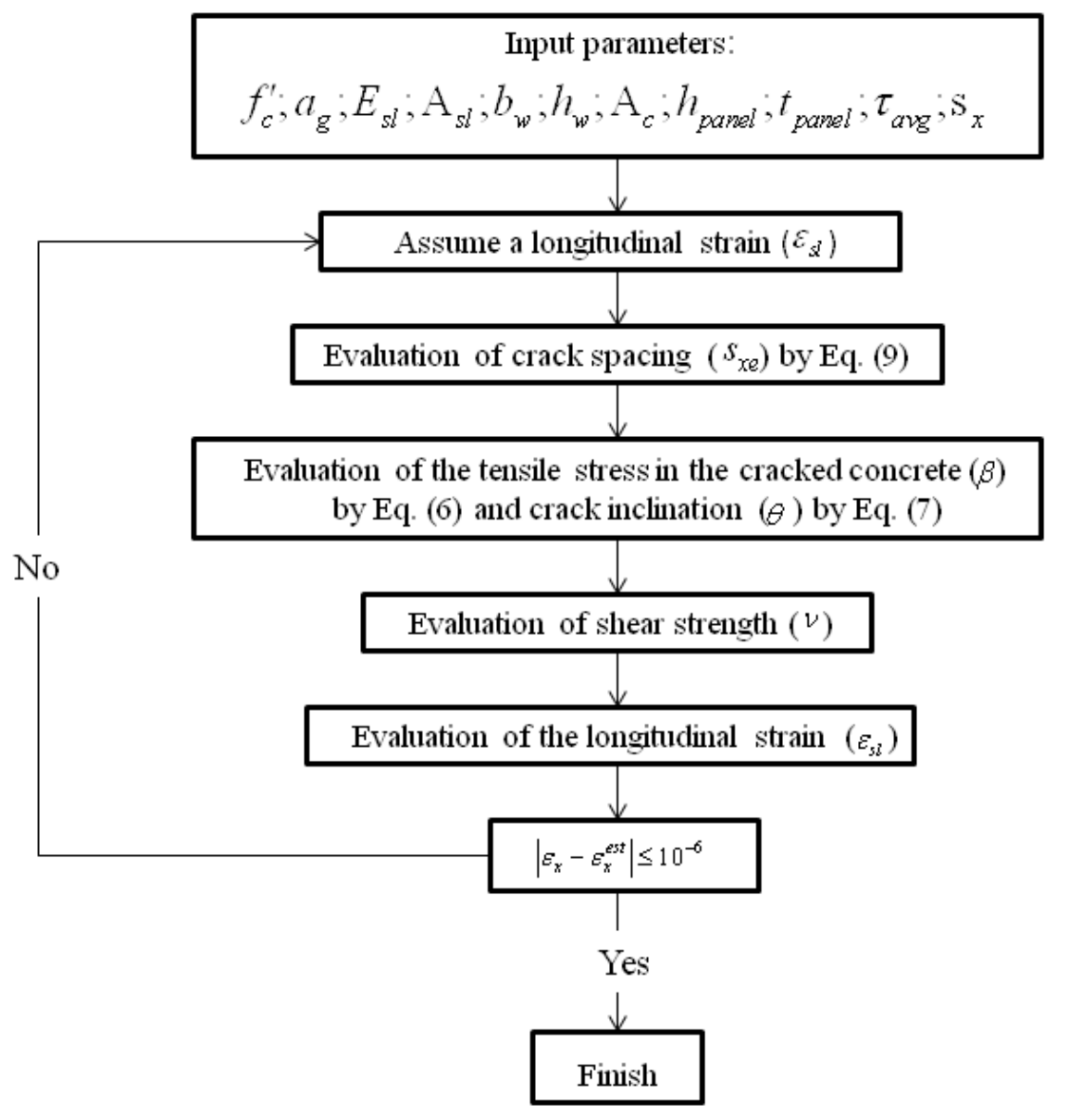

Figure 14. Calculation procedure of SMCFT adapted for the strengthening technique with RSFRM panels 


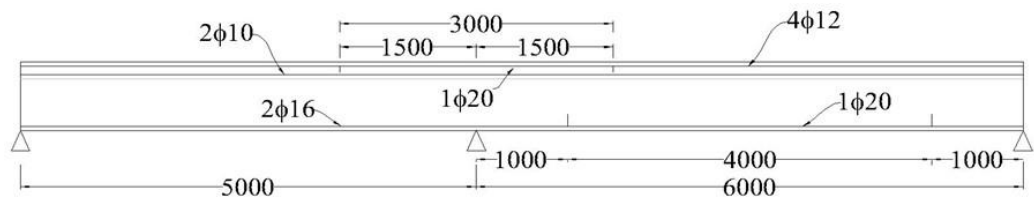

Loading $q=46 \mathrm{kN} / \mathrm{m}$

$\Delta \mathrm{AH}$
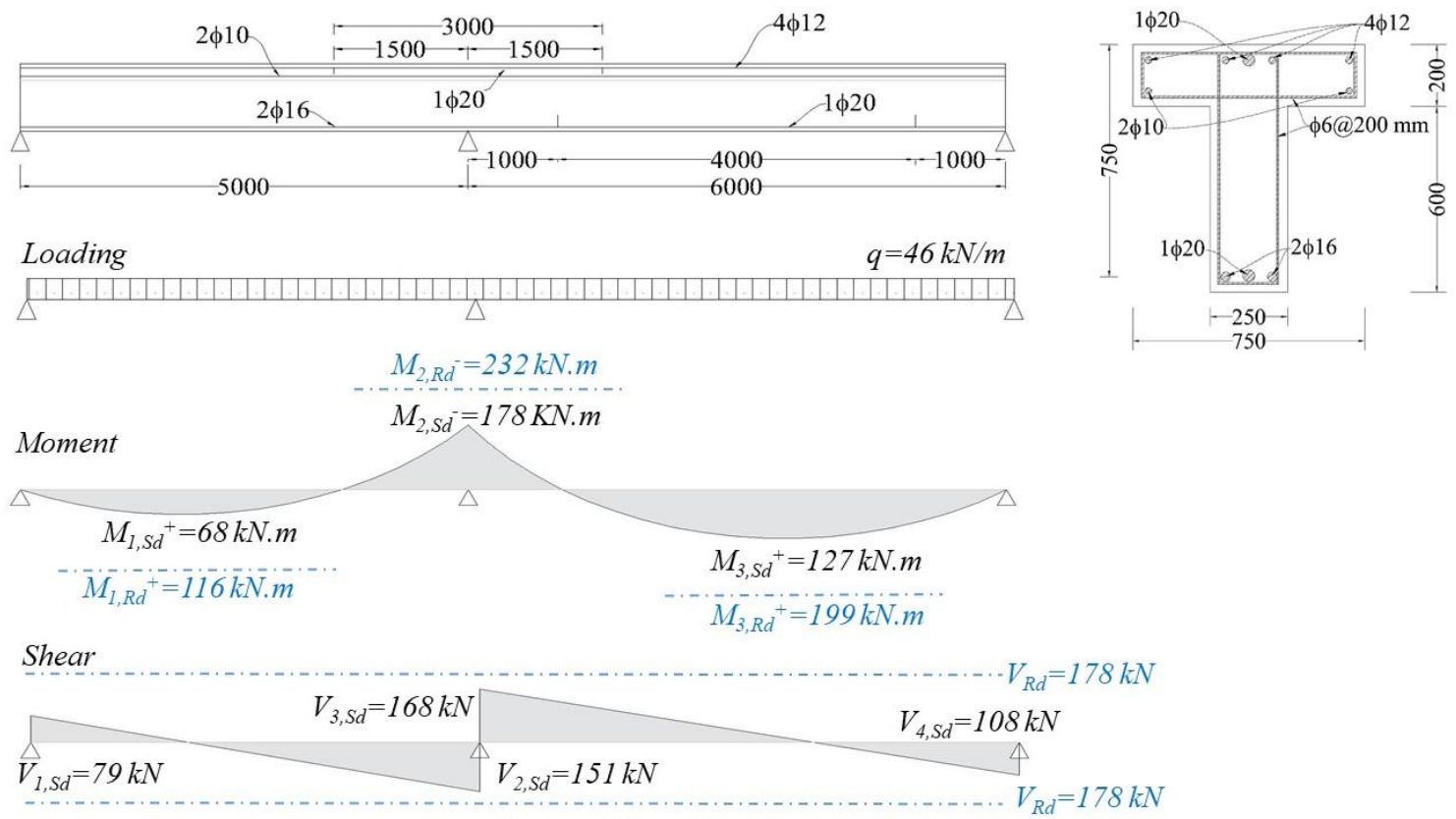

Figure 23. Geometry, loading configuration, and bending moment and shear diagrams of two-span T-cross section RC beam (dimensions in $\mathrm{mm}$ ) 

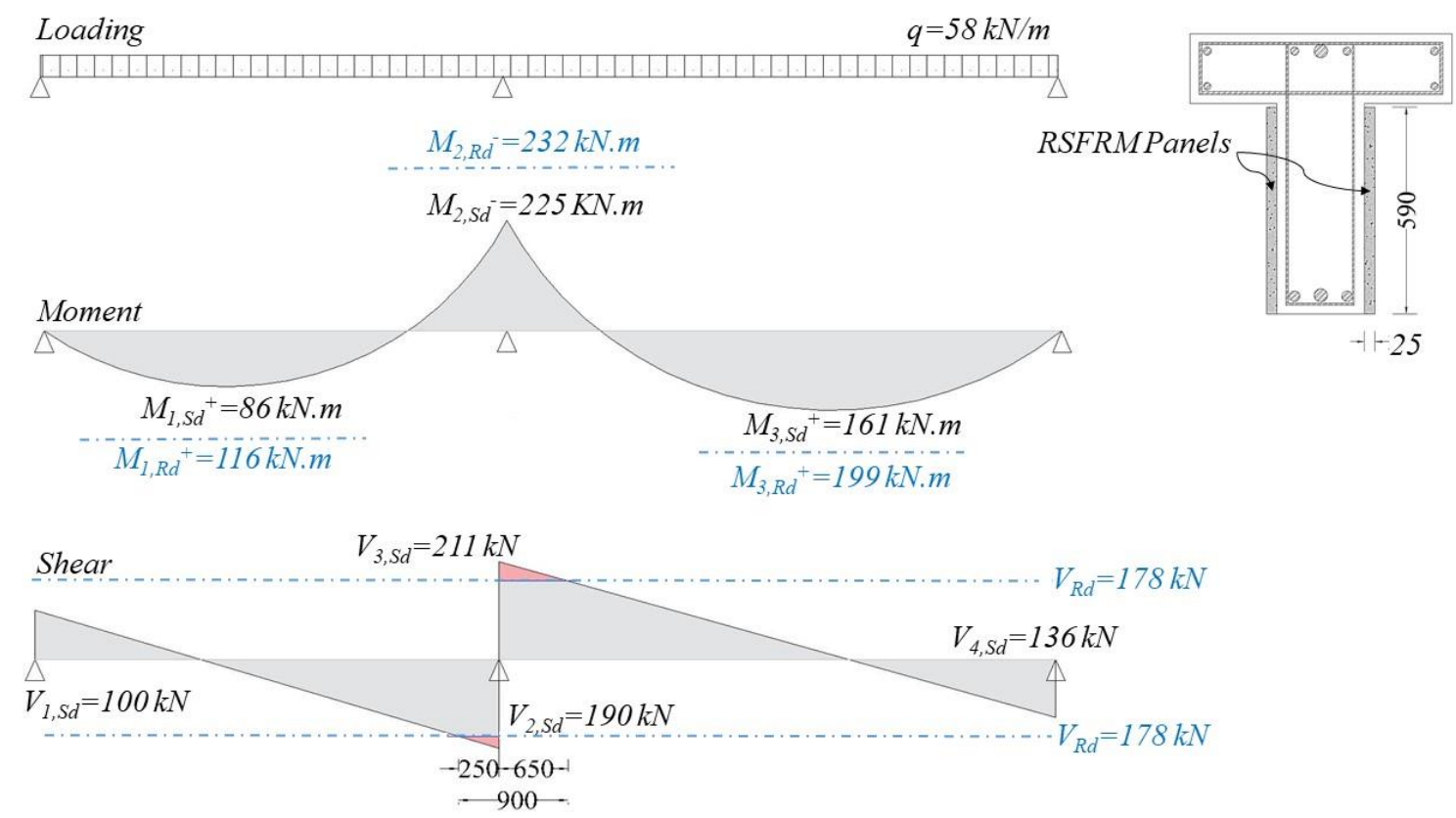

Figure 24. Strengthening geometry, increased live load, and flexural bending moment and shear diagrams of two-span T-cross section RC beam 